\title{
The Spectrum of Aggressive Mastocytosis: A Workshop Report and Literature Review
}

\author{
Roos Leguit ${ }^{a}$ Konnie Hebeda ${ }^{b}$ Marcus Kremer ${ }^{c}$ Jon van der Walt ${ }^{d}$ \\ Umberto Gianelli ${ }^{e}$ Alexandar Tzankov ${ }^{f} \quad$ Attilio Orazi $^{9}$ \\ a Department of Pathology, University Medical Center Utrecht, Utrecht, The Netherlands; ${ }^{b}$ Department of Pathology, \\ Radboud University Medical Center, Nijmegen, The Netherlands; 'Pathology, Städtisches Klinikum München, \\ Munich, Germany; dDepartment of Histopathology, Guy's and St. Thomas' Hospital, London, UK; 'Pathology Unit, \\ Department of Pathophysiology and Transplantation, University of Milan and IRCCS Fondazione Ca' Granda, \\ Ospedale Maggiore Policlinico, Milan, Italy; ${ }^{f}$ Institute of Pathology, University of Basel, Hospital, Basel, Switzerland; \\ gDepartment of Pathology, Texas Tech University Health Sciences Center El Paso, El Paso, TX, USA
}

\section{Keywords}

Bone marrow biopsy · Mastocytosis · European Association for Haematopathology workshop - Mast cell leukemia · Mast cell sarcoma $\cdot$ Aggressive mastocytosis

\begin{abstract}
Most cases of mastocytosis are indolent, usually cutaneous mastocytosis or indolent systemic mastocytosis (SM). Aggressive mast cell (MC) diseases are very rare and often fatal. They can develop de novo or due to progression of indolent forms and can present in different ways; either as MC sarcoma or as advanced SM which includes aggressive SM, MC leukemia, and SM with an associated hematological neoplasm. This review will describe these different aggressive forms of mastocytosis, illustrated by cases submitted to the workshop of the 18th Meeting of the European Association for Haematopathology, Basel 2016, organized by the European Bone Marrow Working Group. In addition, the diagnostic criteria for identifying myelomastocytic leukemia, an ag-
\end{abstract}

gressive myeloid neoplasm with partial MC differentiation that falls short of the criteria for SM, and disease progression in patients with established mastocytosis are discussed.

(c) 2019 The Author(s)

Published by S. Karger AG, Basel

\section{Introduction}

Mast cells (MCs), which derive from CD34+/KIT+ pluripotent hematopoietic progenitor cells of the bone marrow (BM) [1], are normal residents in mucosal tissues and the skin. They have an important role in IgE-associated disorders such as asthma, allergic reactions, and anaphylaxis. Due to the expression of a wide range of surface receptors and their capability of releasing a broad spectrum of mediators, they play a key role in acquired as well as innate immunity $[2,3]$. MCs are multifunctional immune cells exerting both immunostimulatory and immunosuppressive actions and their numbers and anatomical location change markedly during immune responses and karger@karger.com www.karger.com/pat Karger"
(C) 2019 The Author(s) Published by S. Karger AG, Basel

Karger Open access

This article is licensed under the Creative Commons AttributionNonCommercial-NoDerivatives 4.0 International License (CC BYNC-ND) (http://www.karger.com/Services/OpenAccessLicense) Usage and distribution for commercial purposes as well as any distribution of modified material requires written permission.
Roos Leguit, MD

Department of Pathology, University Medical Center Utrecht H04-312, POB 85500

NL-3508 GA Utrecht (The Netherlands)

E-Mail R.J.Leguit-2@umcutrecht.nl 
infections $[3,4]$. MCs express a variety of receptors including the high-affinity receptor for IgE (FceRI) and KIT (CD117) [5]. KIT is a type III transmembrane receptor tyrosine kinase that is also present on a subset of hematopoietic stem cells, germ cells, melanocytes, and interstitial cells of Cajal in the gastrointestinal tract, among others $[6,7]$. KIT is expressed by approximately $1-4 \%$ of nucleated cells in normal human BM, including the majority $(70 \%)$ of CD34+ cells $[6,8,9]$, but on maturation all hematopoietic lineages except MCs downregulate KIT [10]. The ligand of KIT, stem cell factor (SCF), is the major growth factor of MCs in humans [11]. SCF has been associated with proliferation, differentiation, survival, adhesion, chemotaxis, and functional activation of MCs [6] and induces MC development in uncommitted and MCcommitted hematopoietic precursor cells [12].

Mastocytosis is a neoplastic disease involving MCs and their CD34+ progenitors. It is characterized by a clonal proliferation and accumulation of MCs in one or more tissues or organ systems, mostly skin and BM and less frequent gastrointestinal tract, liver, spleen, and lymph nodes, although any tissue can be affected [13]. The World Health Organization (WHO) classification divides mastocytosis into cutaneous mastocytosis $(\mathrm{CM})$, systemic mastocytosis (SM), and MC sarcoma (MCS) [14]. Clinically, mastocytosis includes both indolent and aggressive forms. Indolent forms, which are by far the most frequent, include CM, indolent SM (ISM), and smoldering SM (SSM). Aggressive or high-grade variants of SM, often collectively identified as "advanced SM," include aggressive SM (ASM), SM with an associated hematological neoplasm (SM-AHN), and MC leukemia (MCL) [15]. MCS is also included in the aggressive group. SSM, although considered a nonadvanced SM, nevertheless has higher propensity to progress than ISM.

In mastocytosis, a somatic gain of function mutation in different regions of KIT is present in $>90 \%$ of patients, leading to structural alteration of the protein resulting in constitutive activation of the receptor independent from its ligand [16]. The KIT D816V mutation, first described in mastocytosis patients by Nagata et al. [17], is the most common one, but as many as 33 other mutations in KIT have now been described [18].

The clinical symptoms associated with MC disorders are attributable to the release of histamine and other MC mediators such as tryptase, prostaglandins, leukotrienes, and cytokines. These mediator-related symptoms include pruritus, flushing, blistering, abdominal pain, diarrhea, gastrointestinal hemorrhage, bone pain and, in severe cases, hypotensive episodes, typically seen in the so called "primary MC activation syndrome" [19-21].

The Spectrum of Aggressive Mastocytosis

\section{Histopathological Diagnosis of SM}

$\mathrm{SM}$ is a neoplastic MC disease characterized by the involvement of at least one extracutaneous organ, with or without skin lesions. It is defined by the presence of the major criterion and at least 1 minor criterion, or $\geq 3 \mathrm{mi}$ nor criteria [14]. The major criterion is the presence of multifocal dense infiltrates of MCs ( $\geq 15$ MCs in aggregates) detected in sections of BM and/or other extracutaneous organ(s). The 4 minor criteria are:

(i) $>25 \%$ of the MCs in biopsy sections of BM or other extracutaneous organs are spindle shaped or have atypical morphology, or $>25 \%$ of all MCs in BM aspirate smears are immature or atypical.

(ii) An activating point mutation at codon 816 of KIT in the BM, blood, or other extracutaneous organ.

(iii) MCs in the BM, blood, or another extracutaneous organ express $\mathrm{CD} 25$, with or without $\mathrm{CD} 2$, in addition to normal MC markers.

(iv) Serum total tryptase is persistently $>20 \mathrm{ng} / \mathrm{mL}$, unless there is an associated myeloid neoplasm.

For the subclassification of SM, signs of an excessive $\mathrm{MC}$ burden in the tissue, called B-findings, and signs of specific (MC-related) organ damage, called C-findings, are used to define the different subgroups (Tables 1,2). " $\mathrm{B}$ " in B-findings stands for "burden of disease" C' in Cfindings stands for "cytoreductive therapy requiring." The presence of C-findings (organ dysfunction) is characteristic of ASM and the acute form of MCL.

In BM smears of SM, the following morphologically defined subtypes of MCs can be encountered [22,23]:

(i) Typical tissue MC or well-differentiated MCs (round cells, well granulated, round central nuclei).

(ii) Atypical MC exhibiting elongated cytoplasmic extensions, oval nuclei with excentric position, and a hypogranulated cytoplasm with focal granule accumulation (“atypical MC type I").

(iii) Atypical MC with bi- or multilobed nuclei ("atypical MC type II"), also referred to as promastocytes.

(iv) Metachromatically granulated blast-like cells (metachromatic blasts).

Atypical MCs type I is more commonly seen in SM with a more indolent course, while atypical MCs type II and metachromatic blasts are more commonly seen in MCL and are associated with a significantly shorter survival [22]. An increase of the latter 2 types of MCs over $10 \%$ of all MCs on a BM smear is regarded as "high-grade morphology" [23].

In rare $\mathrm{SM}$ cases, the MCs are mature and well granulated without atypia and absent or low CD2 or CD25 expression (but often CD30 expression). These cases, which 
Table 1. Subdivision of SM and its criteria according to the updated 2016 WHO classification

\begin{tabular}{ll}
\hline SM & Criteria \\
\hline Indolent SM & Criteria of SM and no C-findings \\
Smoldering SM & Criteria of SM, $\geq 2$ B-findings and no C-findings \\
SM-AHN* & Meets criteria of SM as well as those of the AHN \\
Aggressive SM & Criteria of SM and $\geq 1$ C-findings \\
MCL & MCs in BM $\geq 20 \%$ \\
- Typical/classical versus aleukemic variant & - Typical/classic MCL: $\geq 10 \%$ MCs in peripheral blood \\
& - Aleukemic variant: $<10 \%$ MCs in peripheral blood \\
- Acute versus chronic MCL & - Chronic MCL: no C-findings \\
& - Acute MCL: $\geq 1$ C-findings \\
\hline
\end{tabular}

* The previous term SM with clonal hematologic non-mast cell-lineage disease and the new term SM with associated hematologic neoplasm can be used synonymously. WHO, World Health Organization; SM, systemic mastocytosis; SM-AHN, SM with an associated hematological neoplasm; MCL, mast cell leukemia; MC, mast cell.

Table 2. Criteria for $B$ and $C$ findings according to the updated 2016 WHO classification

$B$ findings

- High MC burden (shown on BM biopsy): $>30 \%$ infiltration of cellularity by MCs (focal, dense aggregates) and serum total tryptase $>200 \mathrm{ng} / \mathrm{mL}$

- Signs of dysplasia or myeloproliferation, in non-MC lineage(s), but criteria are not met for definitive diagnosis of an AHN, with normal or only slightly abnormal blood counts

- Hepatomegaly without impairment of liver function, palpable splenomegaly without hypersplenism and/or lymphadenopathy on palpation or imaging

C findings

- BM dysfunction caused by neoplastic MC infiltration, manifested by $\geq 1$ cytopenia: absolute neutrophil count $<1.0 \times 10^{9} / \mathrm{L}$, hemoglobin level $<10 \mathrm{~g} / \mathrm{dL}$, and/or platelet count $<100 \times 10^{9} / \mathrm{L}$

- Palpable hepatomegaly with impairment of liver function, ascites, and/or portal hypertension

- Skeletal involvement, with large osteolytic lesions with or without pathologic fractures*

- Palpable splenomegaly with hypersplenism

- Malabsorption with weight loss due to gastrointestinal tract MC infiltrates

* Pathological fractures caused by osteoporosis do not qualify as a $\mathrm{C}$ finding. WHO, World Health Organization; MC, mast cell; $\mathrm{BM}$, bone marrow; AHN, associated hematological neoplasm.

have been referred to as SM with well-differentiated MCs, may have a low frequency of KIT D816V and are associated with other exon 17 mutations [24-26], which may be responsive to tyrosine kinase inhibitors such as

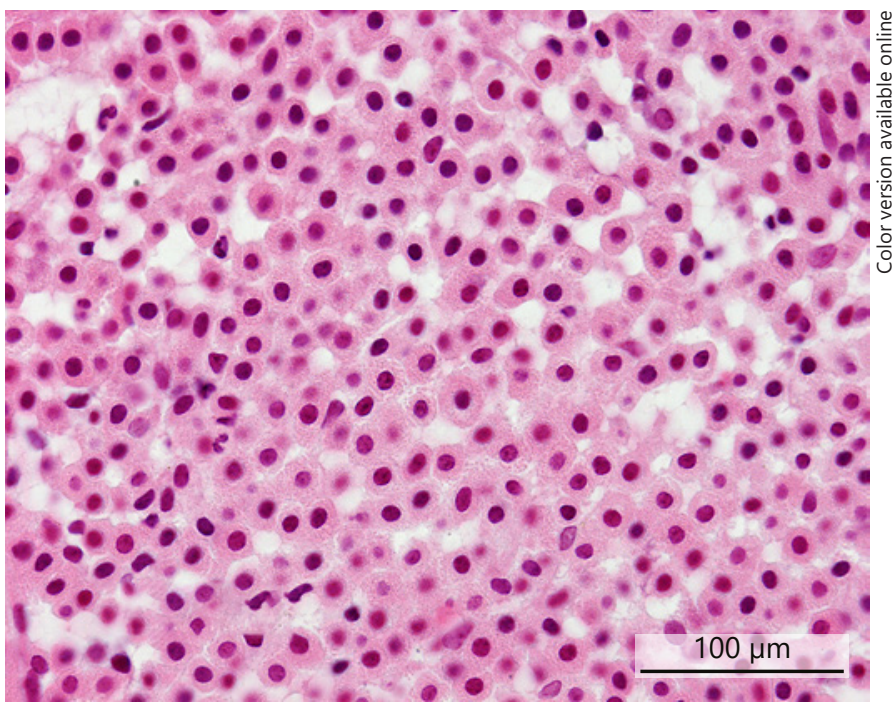

Fig. 1. Well-differentiated SM. BM infiltrates consisting of mature and well-granulated MCs without atypia (case 331, Goswami et al.).

imatinib. A well-differentiated morphology subtype can be encountered in any subtype of SM as is illustrated by case 331 of the workshop, describing a 74-year-old female with SM (SSM/MCL)-AHN (myelodysplastic syndrome [MDS] with ring sideroblasts and multilineage dysplasia) with a well-differentiated morphology of the MCs (Fig. 1), presence of a SF3B1 mutation (K700E) but no KIT D816V mutation, who responded well to imatinib treatment.

Normal MCs are CD30 negative and although initially CD30 expression was reported to be preferentially expressed in neoplastic cells of advanced SM compared to 
ISM [27], this was not confirmed by other studies, which show that at least $80 \%$ of ISM cases also express CD30 [28, 29]. In addition, cases in which the MCs have a well-differentiated morphology can also express CD30.

\section{Mutations in SM}

In SM, KIT D816V mutations are present in $>80 \%$ of cases, most often in ISM (>90\%) and less frequently in advanced SM with the lowest frequencies in MCL (46$68 \%$ ) [30-32]. In MCS, only $21 \%$ of patients have a KIT D816V mutation, whereas $29 \%$ have another KIT mutation (in exon 17, exon 11, or exon 8), and half of MCS cases do not have any detectable KIT mutation [33]. Some of the non-D816V mutations are sensitive to imatinib, and it is therefore important to sequence the whole KIT gene in cases lacking the canonical mutation. In SM, KIT D816V mutations are often also detected in nonMCs (CD34+ hematopoietic progenitor cells, B-lymphocytes, monocytes, neutrophils, eosinophils, and occasionally T-lymphocytes), with variable patterns of involvement, indicating that $\mathrm{SM}$ is a disorder of a pluripotent hematopoietic progenitor cell [24, 34-43]. In Blymphocytes, there is indeed evidence that the KIT D $816 \mathrm{~V}$ mutation occurs before $V /(D) / J$ recombination, prior to the pro-B-cell stage of B-cell differentiation [35]. Significantly more patients with KIT D816V+ advanced SM carry the KIT D816V mutation in their non-MCs myeloid cells compared to patients with KIT D816V+ ISM [24]. Also, significantly more patients with advanced SM carry the KIT D816V mutation in $\geq 2$ populations of myeloid cells compared with those with ISM (81 vs. 27\%) [24]. Flow cytometric studies of BM samples have demonstrated that an immature MC phenotype with aberrant expression of CD25 in the absence of coexisting normal MCs is associated with multilineage involvement by the KIT D816V mutation and a worse progression-free survival [44]. An immature MC phenotype is characterized by decreased expression of proteins known to be acquired during the BM MC maturation process, such as FceRI, CD45 and cytoplasmic MC enzymes (e.g., carboxypeptidase A and total tryptase), and decreased light scatter features (FSC, SSC) [44]. SM without multilineage involvement by the KIT D816V mutation shows a mature, activated phenotype of MCs by flow cytometry and is associated with a better progression-free survival [44]. Thus, a KIT D816V mutation in a more mature and lineage restricted MC progenitor is associated with a more indolent form of disease, whereas a KIT D816V mutation in an undifferentiated progenitor cell with a more immature MC phenotype seems to lead to multi- lineage involvement by the KIT D $816 \mathrm{~V}$ mutation and a more aggressive form of disease.

The KIT median variant allele frequency (VAF) is strongly correlated with disease activity as represented by the serum tryptase level, disease subtype (indolent versus advanced SM) and survival, but not with the degree of MC infiltration of the BM $[18,45,46]$. The lack of correlation between the VAF and the degree of MC infiltration in the BM may be explained by the fact that non-MClineage cells in the BM also harbor a KIT mutation but at levels that may greatly vary from patient to patient [18]. Significantly different KIT D816V VAFs have been observed within the ASM/MCL group for patients with or without AHN (38 vs. $22 \%$ ), with or without monocytosis $>1 \times 10^{9} / \mathrm{L}$ ( 45 vs. $29 \%$ ), and with or without elevated serum levels of alkaline phosphatase (ALP) and $\gamma$-glutamyl transpeptidase $>2 \times$ upper limits of normal (33 vs. 11\%) [46]. The presence of a high KIT D816V VAF in the peripheral blood in patients without circulating MCs is highly predictive of an AHN.

KIT D816V can be detected in peripheral blood leukocytes of most patients with SM when highly-sensitive qPCR techniques are used [44, 45-47]. In a consensus paper of the members of the European Competence Network on Mastocytosis, recommendations for the routine screening of adult patients with suspected mastocytosis are: to test peripheral blood cells for KIT mutations by using a highly sensitive assay, in combination with measurement of serum tryptase and other relevant parameters, such as specific clinical symptoms indicating potential organ involvement, followed by the investigation of the BM and sequencing of the KIT gene in case of negative results [18]. Serial measurements of the KIT D816V VAF by highly sensitive techniques appear useful for monitoring of residual disease in aggressive subtypes during or after cytoreductive therapy or allogeneic stem cell transplantation $[45,46]$.

As in other myeloid neoplasms, additional mutations in genes encoding for epigenetic regulators (ASXL1, EZH2, IDH2, TET2), splicing factors (SRSF2, SF3B1, $U 2 A F 1$ ), signaling molecules (CBL, JAK2, N/KRAS), or transcription factors (RUNX1) have been reported in SM with significantly higher mutation frequencies in advanced SM than in ISM/SMM $[36,48]$. The currently favored mechanistic concept of aggressive SM pathogenesis is of a multimutated neoplasm, in which mutations in TET2, SRSF2 and/or ASXL1 in a pluripotent hematopoietic precursor cell precede the KIT D816V mutation, and the latter rather represents a "phenotype modifier" of clonal hematopoietic stem cell disorders toward SM [49]. 
Table 3. Cases submitted to the workshop "Aggressive Mastocytosis" of the 18th Meeting of the EAHP, Basel 2016, organized by the European Bone Marrow Working Group

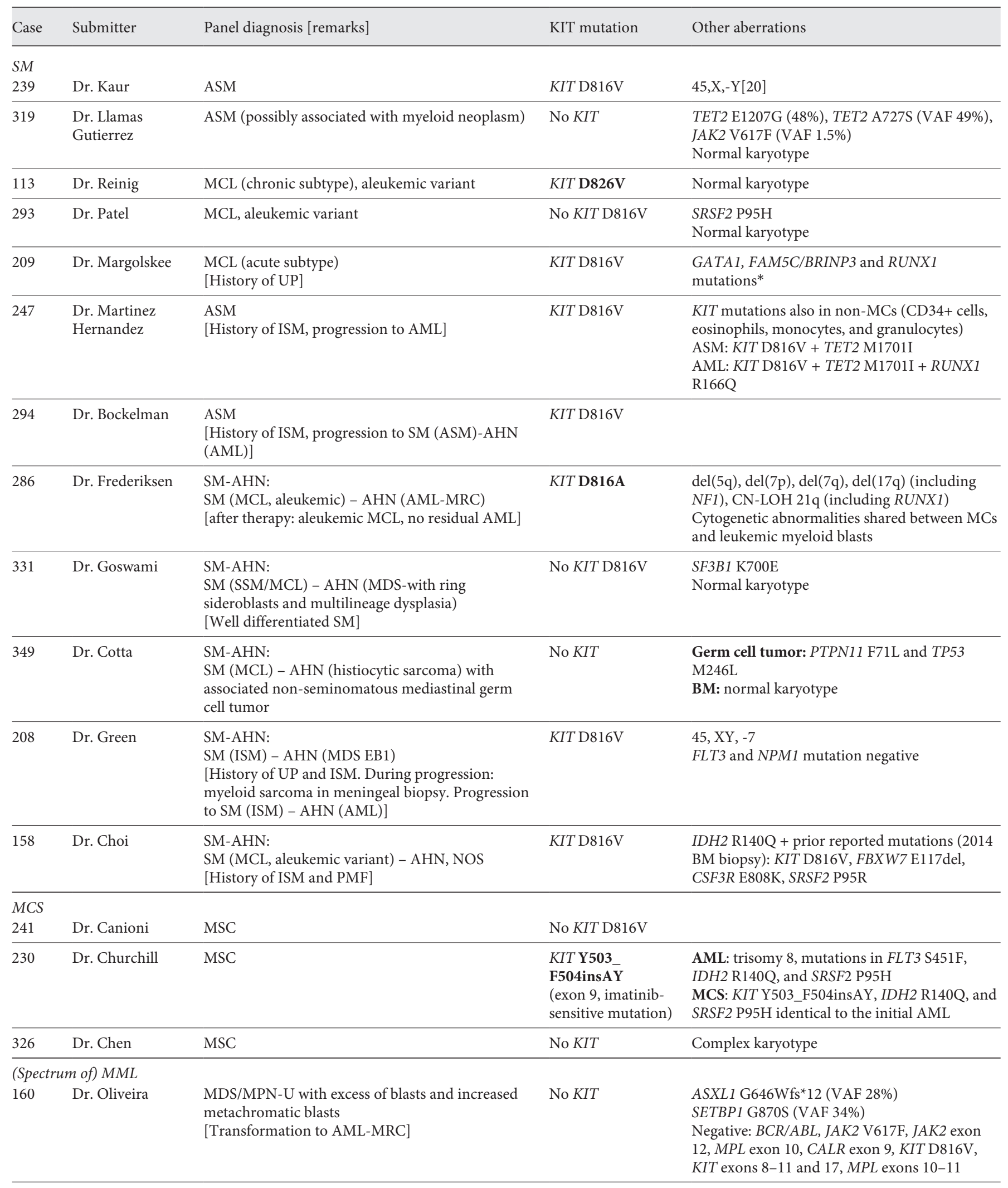


Table 3 (continued)

\begin{tabular}{lllll}
\hline Case & Submitter & Panel diagnosis [remarks] & KIT mutation & Other aberrations \\
\hline 193 & $\begin{array}{l}\text { Dr. Ziarkiewicz- } \\
\text { Wróblewska }\end{array}$ & Myeloid neoplasm most consistent with MCL & No KIT & Normal karyotype \\
\hline $\begin{array}{l}\text { Cutaneous mastocytosis (aggressive) } \\
111 \quad \text { Dr. Petrusevska }\end{array}$ & $\begin{array}{l}\text { Diffuse cutaneous mastocytosis with severe } \\
\text { systemic involvement and rapidly fatal outcome }\end{array}$ & Not available & Not available \\
\hline
\end{tabular}

SM, systemic mastocytosis; ISM, indolent systemic mastocytosis; ASM, aggressive systemic mastocytosis; MCL, mast cell leukemia; MCS, mast cell sarcoma; UP, urticaria pigmentosa; SSM, smoldering systemic mastocytosis; AHN, associated hematological neoplasm; MML, myelomastocytic leukemia; AML, acute myeloid leukemia; MRC, myelodysplasia-related changes. * Exact mutation type not available.

This review describes the different forms of aggressive mastocytosis, illustrated by cases submitted to the workshop of the 18th Meeting of the European Association for Haematopathology, Basel 2016, organized by the European BM Working Group (Table 3).

\section{Advanced SM}

SM as a group is already rare, making up only $1.5 \%$ of all myeloid tumors [50], but advanced SM is even rarer. The average incidence rate for all subtypes of SM combined, including urticaria pigmentosa (UP), was 0.89 per 100,000 per year in patients of $\geq 15$ years in the Danish nationwide cohort study for the period between 1997 and 2010 , with a prevalence of 9.59 per 100,000 inhabitants [51]. Cases of UP were included as "probable ISM" as most adults with UP will show SM when fully investigated $[13,52]$. Depending on the study group, the distribution between ISM and advanced SM varies greatly, probably due to referral bias. In the study from the Dermatology, Clinical Immunology and Allergy departments in Rotterdam, the Netherlands, ISM accounted for as much as $91.2 \%$ of SM patients, whereas ASM (5.1\%), SM-AHN (3.7\%), and MCL (0\%) were relatively rare [53]. In contrast, studies from specialized hematology (Mayo Clinic, US) and hematopathology (University of Lübeck, Germany) departments report much lower frequencies of ISM (46 and 55\%, respectively) and higher frequencies of advanced SM, with SM-AHN being most frequent (40 and $31 \%$, respectively), followed by ASM (12 and $11 \%$, respectively) and MCL (1 and 3\%, respectively) [51, 54]. However, a more reliable representation of the actual distribution of ISM and advanced SM is probably provided by the Danish nation-wide study and an Italian multicenter study, which report a relatively high frequency of

The Spectrum of Aggressive Mastocytosis
ISM (82-89\%) and low frequency of advanced SM (7\%), consisting of SM-AHN (4-5\%), ASM (2-6\%), and MCL $(0.2-1 \%)$, with $11 \%$ in the Denmark study of unknown subtype $[32,51]$. Recently, similar results have been published from the data registry of the European Competence Network on Mastocytosis, which included more than 3,000 patients from 12 countries and 25 centers, with only $12 \%$ of cases consisting of advanced mastocytosis [55]. While patients with ISM have a nearly normal life expectancy, advanced SM displays a poor prognosis with a median overall survival (OS) of 2-31, 24-85 and 41 months for patients with MCL, SM-AHN and ASM, respectively [30-32, 54, 56, 57].

In advanced SM, KIT is the most commonly mutated gene but other mutated genes in addition to KIT are found in at least $80 \%$ of patients $[36,58,59]$. The most frequently affected genes in advanced SM besides KIT are TET2 (27-47\%), SRSF2 (36-48\%), ASXL1 (14-29\%), RUNX1 (13-23\%), JAK2 (13-16\%), N/KRAS (12-14\%), CBL (11-13\%), and EZH2 (10\%) [36, 58, 59]. Less frequently affected genes $(<10 \%)$ are $I D H 1 / I D H 2, E Z H 2$, ETV6, U2AF1, SF3B1, MLL, NPM1, ETNK1, DNMT3A, SETBP 1 , and TP53 $[48,58,59]$. Sometimes, 2 or more different mutations are present in the same gene, most frequently in TET2 and occasionally in ASXL1, RUNX1, $K R A S$, or $U 2 A F 1[36,59]$. In $60-78 \%$ of patients with advanced $S M, \geq 2$ mutated genes in addition to KIT D816V could be detected $[36,59]$, with $41 \%$ of advanced SM patients even having $\geq 3$ additional mutations [36]. Patients with advanced SM, who lack additional mutations present clinically with a less aggressive phenotype, lack significant cytopenia and show a significantly longer OS [36]. In KIT D816V+ advanced SM patients, the accumulation of SRSF2/ASXL1/RUNX1 (S/A/R) mutations was shown to correlate with OS. The 3 -year OS was $90 \%$ in patients with 0 of the genes in the panel mutated, $73 \%$ in 
patients with 1 mutated gene, and $42 \%$ in patients with $\geq 2$ mutated genes in the $(S / A / R)$ panel [59]. As individual markers, ASXL1 and RUNX1 mutations have most consistently been associated with inferior OS in advanced SM $[57,59,60]$. The SRSF2-P95 hotspot mutation, a mutation correlating with advanced SM [48], has been shown to be a poor risk marker for OS in KIT D816V+ advanced SM in one study [59], but this could not yet be confirmed by others [60]. Although in SM, TET2 mutations were correlated with inferior OS in one study [61], and TET2 mutations were statistically associated with aggressive forms of SM in another study [62], the prognostic effect of isolated TET2 mutations in advanced SM could not be confirmed in a third study [59].

An abnormal karyotype is uncommon in SM and mostly seen in SM-AHN, were it is found in as many as $19-32 \%$ of cases, primarily those with an associated myeloid neoplasm [32, 58, 63, 64].

- ASM is far less common than ISM [24, 32, 50, 51, 54, $55,65,66]$. It meets criteria for $S M$, has $\geq 1$ C-findings indicating organ damage by infiltration of MCs, but has no evidence of MCL. C-findings include severe cytopenias, hepatomegaly, splenomegaly, large osteolytic bone lesions, and evidence of severe GI-malabsorption, for example, more than $10 \%$ of body weight over a fixed period of time (Table 2). It must be said, however, that inclusion of osteolytic bone lesions is quite controversial as a C-finding, as even in a group of expert hematologists studying on advanced SM, no agreement on how "large" should be defined, has been reached. MC infiltration leading to marked organomegaly should not be regarded as a C-finding unless accompanied by signs of impaired organ function, since significant organomegaly is also found in patients with an indolent or a smoldering course, and is then regarded as a B-finding [14]. Although skin lesions may occur in ASM, they are usually absent. Patients with ASM frequently display constitutional symptoms (60\%), hepatosplenomegaly (50\%), and lymphadenopathy (30\%) [65]. A KIT D816V mutation is present in $\sim 80 \%$ of ASM [65]. Atypical MCs type II and metachromatic blasts in the BM smear are correlated with a significantly shorter survival, especially when the percentage increases to $5 \%$ or more of all nucleated BM cells $[22,23]$. When the percentage of MCs in the BM aspirate reaches $20 \%$, the diagnosis changes to MCL [23]. Cases of ASM with 5-19\% MCs in BM smears and rapid progression seem to be an imminent prephase of MCL and have been suggested by the EU/US-consensus group and the European Com- petence Network on Mastocytosis to be termed ASM in transformation to MCL [23]. Leukemic transformation (to MCL or acute myeloid leukemia [AML]) occurs in $5-32 \%$ of ASM $[32,54]$. Overall median survival in ASM is 41 months $[32,54]$.

Two de novo cases of ASM, case 239 and case 319, were submitted to the workshop (Table 3). The patient in case 239 was a 75 -year-old male with leukocytosis, persistent thrombocytopenia, fatigue, anorexia, joint pain, and elevated tryptase. His BM showed spindle-shaped MCs, singly and in aggregates, with aberrant expression of CD25 and CD2. A KIT D816V mutation was present. The persistent and severe thrombocytopenia was considered to represent a C-finding, classifying this case as ASM. He passed away 3 years later. The patient in case 319 was a 64-year-old female with pancytopenia, palpable splenomegaly, and elevated tryptase. Mutations were detected in TET2 (VAF: 49\%) and JAK2 V617F (VAF: 1.5\%). An associated myeloid neoplasm was possibly present, but could not be finally diagnosed.

- $M C L$ is a rare and aggressive form of SM seen in $<5 \%$ of SM patients and is rapidly fatal with a median survival of 2-31 months [24, 30-32, 50, 51, 54, 55, 57, 66, 67]. It is defined as SM with MCs $\geq 20 \%$ of marrow cells in a BM aspirate and/or $\geq 10 \%$ of total white blood cell count in the peripheral blood, which is usually atypical, immature looking (promastocytes) and may include metachromatic blasts. The BM biopsy shows diffuse infiltration by atypical, immature MCs, but the threshold of $20 \%$ of BM MCs is based on cytologic analysis of BM smears. Although MCL may involve several different organ systems, skin lesions are usually absent [23]. Mediator-related symptoms consistent with MC activation are frequently present [30]. MCL can occur de novo (primary MCL) or secondary, when an anteceding MC neoplasm is present [23, 30, 31]. In a consensus paper of the EU/US-consensus group and the European Competence Network on Mastocytosis, secondary MCL is defined as transformation of SM (usually ASM) or MCS [23]. The vast majority of secondary MCLs evolve from SM-AHN (83-86\%) and a minority from ASM, whereas direct evolution of MCL from ISM is rare [31, 54].

MCL can be further subdivided in chronic versus acute MCL and leukemic versus aleukemic MCL [23]. Distinction between chronic versus acute MCL is based on the presence of C-findings; chronic MCL has no C-findings, whereas acute MCL has $\geq 1 \mathrm{C}$-finding [23]. Acute MCL is the most frequent (67-93\%) and follows a more aggressive course than chronic MCL $[31,56]$. Chronic MCL 

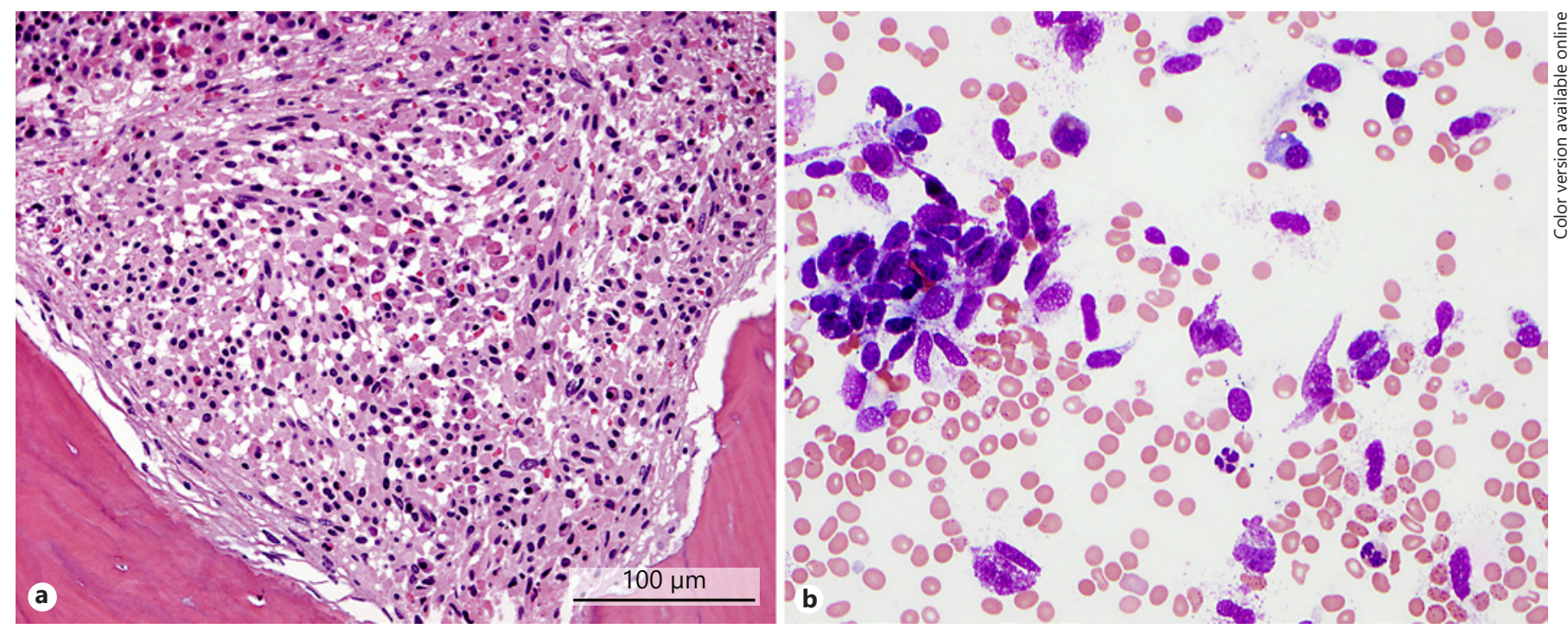

Fig. 2. MCL. a BM with diffuse infiltration by atypical MCs (chronic MCL, case 113, Reinig et al.). b BM aspirate with $\geq 20 \%$ atypical MCs (acute MCL, case 293, Patel et al.).

may display a well differentiated MC morphology. Distinction between leukemic (a.k.a. "typical" or "classical") MCL and aleukemic MCL is based on the number of circulating MCs; in leukemic MCL at least $10 \%$ of blood leukocytes are MCs [23]. The aleukemic variant is the most frequent, accounting for $62-93 \%$ of MCL cases in the largest studies; outcome in both variants is equally poor $[30,31]$.

A KIT D 816 V mutation is found in only $46-68 \%$ of cases of MCL [30,31], being lower than in other advanced SM subtypes. Other KIT mutations are relatively frequent $(\sim 20 \%)$ and $7-11 \%$ of cases show wild-type KIT [30, 31]. As such cases with non-KIT D816V mutations or wildtype KIT are relatively frequent and may respond to tyrosine kinase inhibitors such as imatinib $[24,25]$, complete gene sequencing is necessary in any MCL case when no KIT D816V mutation is detected. As mentioned before, other commonly observed concurrent mutated genes in MCL are TET2, SRSF2, ASXL1, and K/N-RAS. At least one of the latter 3 mutations is found in $52 \%$ of patients with MCL, which is associated with a poorer outcome [31].

Case 113 submitted to the workshop illustrates an example of chronic MCL (Fig. 2a). Criteria for C-findings were not met, and mediator-related symptoms were absent in this patient, consistent with this more indolent variant of MCL. Case 293 submitted to the workshop is an example of acute MCL, aleukemic variant (Fig. 2b). NGS in this case revealed an isolated SRSF2 mutation
(p.P95H). No KIT D816V mutation was found. Case 209 of the workshop is a rare example of a secondary MCL, which evolved in a patient with a history of UP for 28 years. The MCs in this case were CD25 and CD2 negative; KIT D816V and RUNX1 mutations were detected.

- $S M-A H N$ is the shortened name for what was previous called SM with associated clonal hematological nonMC lineage disease (SM-AHNMD). By definition, SM-AHN fits the WHO criteria for both SM and a non-MC hematological neoplasm, being MDS, myeloproliferative neoplasm (MPN), MDS/MPNs such as chronic myelomonocytic leukemia (CMML), atypical chronic myeloid leukemia, $B C R-A B L 1$ negative, $\mathrm{MDS} /$ MPN unclassifiable, or AML in $80-90 \%$ of cases [50, $57,65,68,69]$. Rare cases of SM have been associated with lymphoma, chronic lymphocytic leukemia, plasma cell neoplasms, or primary amyloidosis $[38,50,57$, $63,65,69,70]$. The SM component may be either ISM, SSM, or advanced SM (ASM or MCL). Skin lesions may or may not be present. The AHN is diagnosed concomitantly with SM in the majority of patients (67\%), but there may be a long interval (3-370 months) between the time of diagnosis of the SM and the diagnosis of the AHN [57]. Prognosis mainly depends on the associated AHN $[57,63,69]$. Overall median survival in SM-AHN is $24-85$ months [32, 54, 578, 65].

In the presence of an increased number of BM MCs combined with eosinophilia, the possibility of one of the Myeloid/Lymphoid Neoplasms with Eosinophilia and 
Rearrangement of PDGFRA, PDGFRB, FGFR1 or PCM1$J A K 2$ should be considered, as these cases may show a marked increase in spindle-shaped atypical MCs with aberrant CD25 expression, lying scattered or forming noncohesive or cohesive clusters [14, 71]. These MC aggregates (which may or may not meet criteria for $S M$ ) are mostly seen in cases with PDGFRA and PDGFRB rearrangement and rarely in cases with FGFR1 rearrangement [72]. These diseases, which often show hematological features of chronic eosinophilic leukemia but can also present as AML or lymphoblastic lymphoma, are often associated with splenomegaly, marked elevation of serum vitamin B12 and elevation of serum tryptase [14]. Since these cases are usually sensitive to treatment with imatinib [69], screening for PDGFRA/PDGFRB-rearrangement, especially FIP1L1-PDGFRA, is warranted in all cases of MC hyperplasia with eosinophilia [73, 74]. In addition, a new tyrosine kinase inhibitor, called pemigatinib, shows promising results in FGFR1 rearranged cases, which were until now very aggressive and treatment resistant (https://www.cancer.gov/publications/dictionaries/cancer-drug/def/fgfr-inhibitor-incb054828).

KIT mutations are the most frequent alteration in SMAHN, found in about $85 \%$ of patients [57] and in up to 94\% if MCs are microdissected and highly sensitive techniques are used [38]. The KIT D816V mutation may also be detected in cells belonging to the AHN $[24,38,75]$. This is seen particularly in SM-CMML where it is found in CMML cells in $89 \%$ of cases, suggesting a common (MC/monocytic) precursor cell from which both the SM and AHN component arise [38]. In other forms of SMAHN, such as SM-AML and SM-MPN, the frequency of a KIT mutation in the AHN is much lower, occurring in only 30 and $20 \%$ of cases, respectively [38]. In some of these cases, the KIT D $816 \mathrm{~V}$ mutation may not be the initiating molecular genetic event, but rather an additional hit in the pathogenesis [63]. Studies, including non-KIT mutations, have indeed demonstrated the presence of multiple subclones in SM-AHN, supportive of a multihit theory, in which the KIT might occur before, or, more often, after the non-KIT mutation [48, 49]. In those cases, KIT D816V is seen as a phenotype modifier toward SM [49], a hypothesis supported by the fact that in murine primary hematopoietic cells, expression of KIT D816V induces differentiation into MCs in the presence of SCF [76]. In general, TET2 and SRSF2 are considered early events $[36,49]$. Lastly, there are cases of SM-AHN in which a KIT mutation is not present in the AHN cells. This is especially seen in cases with associated lymphoid/ plasma cell neoplasms $[24,38]$. In those cases, the cells of
SM and of the AHN might have different clonal origins, but coincidental presentation [63]. Therefore, possibly different mechanisms may be involved in SM-AHN [63].

Additional non-KIT mutations are frequently present in patients with SM-AHN [36, 49, 57, 59, 77]. Non-KIT mutations are more frequent in advanced SM (ASMAHN and MCL-AHN), irrespective of the AHN subtype and consist mainly of mutation in TET2, SRSF2, ASXL1, RUNX1, N/KRAS, or IDH2 [59]. In ISM-AHN, non-KIT mutations are less frequent and consist mainly of mutations in JAK2, ETV6, U2AF1, EZH2, and SF3B1 [36, 59]. In multivariate analysis, the presence of an ASXL1 or SRSF2 mutation has been shown to be an independent prognostic factor, negatively affecting OS $[57,59]$.

Karyotypic abnormalities are detected $19-32 \%$ of patients with SM-AHN, mostly deletions (del[5q], del[1q], $\operatorname{del}[12 \mathrm{q}]$, less frequently del[7q]), followed by trisomies $(+8)$, monosomies $(-7)$, and complex karyotypes $[32,58$, $63,64]$. Although a poor-risk karyotype was initially reported to be an unfavorable prognostic factor, with $70 \%$ of patients with poor-risk karyotype progressing to AML or MCL versus $17 \%$ of patients with a good-risk/normal karyotype independent from the mutation status [58], this was not confirmed by multivariate analysis in a more recent study [64]. Furthermore, a higher incidence of SM in AML with $t(8 ; 21)$ has been reported, and therefore routinely performing tryptase stains on all AML with $\mathrm{t}(8$; 21) is recommended [78].

Seven cases of SM-AHN submitted to the workshop illustrate the broad spectrum of both the SM and the AHN components. In 4 cases, the SM and AHN components were diagnosed simultaneously. In 3 of those, the SM component was MCL. The AHN component being MDS-RS-MLD (case 331), AML-myelodysplasia-related change (case 286) or histiocytic sarcoma (case 349). In 3 cases, there was a preceding ISM, and in all the evolving AHN was AML (case 247, 294, and 208). By the time the AML was diagnosed, the ISM had progressed to ASM in 2 of the cases (cases 247 and 294). Case 349, classified as SM (MCL)-AHN (histiocytic sarcoma), had an additional mediastinal non-seminomatous germ cell tumor. The histiocytic sarcoma was diagnosed in a biopsy of a gingival mass. BM biopsy identified MCL as well as the histiocytic sarcoma, both negative for the KIT D816V mutation. The mediastinal mass was diagnosed as a mixed germ cell tumor with yolk sac tumor and sarcomatoid carcinoma, which had a PTPN11 F71L and a TP53 M246L mutations. The patient died 10 months after initial diagnosis. Mediastinal germ cell tumors, which account for $1-3 \%$ of extragonadal germ cell tumors, are associated
Leguit/Hebeda/Kremer/van der Walt/ Gianelli/Tzankov/Orazi 


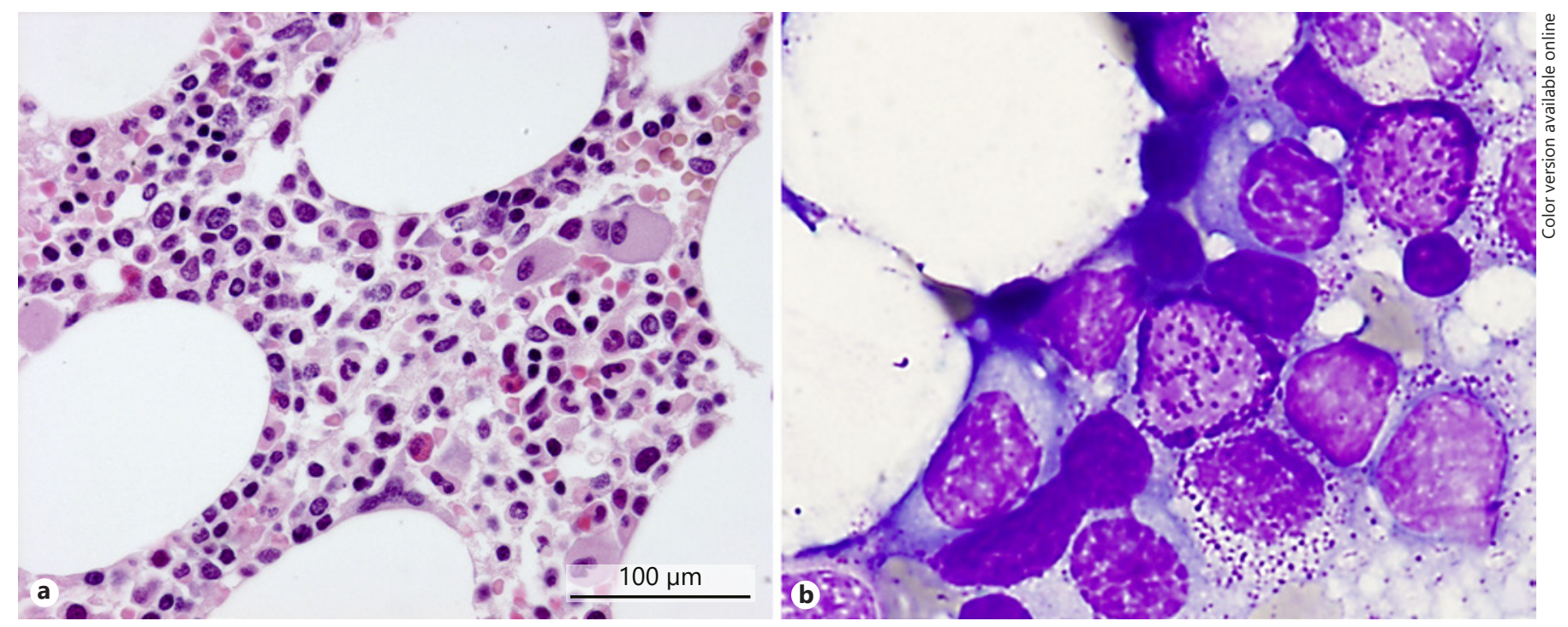

Fig. 3. MDS/MPN-U with excess of blasts and increased metachromatic blasts. a BM biopsy with trilinear dysplasia. b BM smear showing several metachromatic cells (case 160, Oliveira et al.).

with several types of hematological malignancies, particularly myeloid neoplasms [79-81]. They have been associated with histiocytic sarcoma as well as SM [80, 82-84]. The first report of SM associated with a mediastinal germ cell tumor was published in 1991 [85].

\section{Myelomastocytic Leukemia}

Myelomastocytic leukemia (MML) is a rare disease. As currently defined according to the EU/US-consensus group and the European Competence Network on Mastocytosis, myelomastocytic differentiation is "mastocytic differentiation in advanced myeloid neoplasms without evidence of SM" [23]. In the updated WHO 2016 classification, it is not included as a separate entity. Advanced myeloid neoplasms with MML-type disease include MDS (usually with excess of blasts), AML, or the accelerated/ blast phase of MPN or MDS/MPN overlap syndromes with $\geq 10 \%$ immature atypical MCs (atypical MC type II/ promastocytes or metachromatic blasts) in the peripheral blood and/or BM smear. The metachromatic blasts are cells of MC lineage, immunophenotypically (CD117+, tryptase+), and by electron microscopy, and have a blastlike morphology [86]. Mature MCs may also be observed [87]. Molecular studies provide evidence that the MCs in MML are derived from the same leukemic clone as the myeloid neoplasm [86]. Peripheral blood and BM smears typically show dysplasia, and the serum tryptase level is elevated [23, 87, 88]. Patients frequently present with symptoms due to inappropriate release of MC mediators [88]. The BM shows a diffuse interstitial increase in MCs, but not the multifocal dense MC infiltrates of $\geq 15 \mathrm{MCs}$ typical of SM. Moreover, expression of CD2 or CD25 in MCs as well as a KIT D816V mutation are typically lacking $[23,88,89]$, although occasional expression of CD25 has been described [87]. Thus, criteria for SM are not met. MML should be differentiated from AML with tryptase expression and from MCL. MCL is easily distinguished from MML, as $20 \%$ or more MCs are seen in BM aspirate smears of MCL while MML is accompanied by an increase of myeloblasts and lacks criteria for SM [87-89]. Tryptase-positive AML usually has an immunophenotype compatible with AML with minimal differentiation or without differentiation (the French-American-British M0 or M1 subgroup) with CD34-positive myeloblasts showing coexpression of tryptase, mostly without CD117 coexpression [88]. Although nongranulated blasts with coexpression of CD34, CD117, and tryptase or a few metachromatic blasts are occasionally seen in tryptasepositive AML, these are scarce, and a percentage of metachromatic blasts belonging to the MC lineage (CD117+/ CD34-) of $\geq 10 \%$ of all nucleated cells establish the diagnosis MML [88]. Histopathological, clinical, and laboratory features of MML, the diagnostic criteria and its differential diagnosis are described in more detail in several papers $[23,87,88,90]$. The prognosis of MML is grave, with most patients surviving only a few months [86]. 
Two challenging cases (cases 160 and 193) were submitted to the workshop that either fall in the spectrum of MML or in which MML was considered, but which could not be classified further. Case 160 was a 61-year-old female patient with a history of microcytic hypochromic anemia resolving after iron substitution and an unexplained sustained thrombocytosis. Tryptase was elevated, but there were no symptoms of MC disease. The BM biopsy was normocellular with moderate to marked megakaryocytic hyperplasia showing loosely grouped dysplastic megakaryocytes (Fig. 3a). There were benign lymphoid aggregates, but neither MC clusters nor spindled MCs were present. The BM aspirate was cellular with trilineage hematopoiesis, increased megakaryocytes with a subset of small dysplastic forms, and an increase of myeloblasts (morphological 5\% myeloblasts, by flow 9\% CD34/CD117-positive cells). In addition, there were increased metachromatic cells (Fig. 3b), some with fine chromatin, others bilobed, but mature MCs were not increased. Immunohistochemistry showed $10 \%$ dispersed round cells coexpressing CD34, CD117, and tryptase, but CD25 was negative. NGS revealed mutations in ASXL1 (VAF 28\%) and SETBP1 (VAF 34\%), but no mutations in JAK2 V617F or exon 12, MPL exons 10-11, CALR exon 9, or KIT D816V exons $8-11$ or exon 17. The panel favors the diagnosis of MDS/ MPN-U with excess of blasts and increased metachromatic blasts. There was also an increased number of mature appearing MC. The case eventually transformed to AML with myelodysplasia-related changes. Although the possibility of MML was raised by the submitter and considered by the panel, the positivity for CD34 of the blasts together with the $<10 \%$ metachromatic cells makes this unlikely.

Case 193 was a 30 -year-old male patient presenting with severe pain in the lumbar region, dyspnea, dizziness, loss of appetite for 3 months, weight loss, and several bouts of fever reaching $39^{\circ} \mathrm{C}$. He was found to have massive hepatosplenomegaly, abdominal and thoracic lymphadenopathy with pleural effusion and ascites. Hemophagocytic lymphohistiocytosis was clinically diagnosed, and he was treated with a hemophagocytic lymphohistiocytosis regimen. No peripheral blood smear was submitted for review. BM biopsy showed large atypical cells with CD30 positivity leading to a diagnosis of anaplastic large cell lymphoma (ALCL), ALK-negative. The patient continued to deteriorate, developed diffuse intravascular coagulation, and died. $\mathrm{BM}$ aspirate smears were hypocellular and revealed scant normoblastic erythropoiesis, normal granulopoietic maturation, $13 \%$ lymphoid cells, $2 \%$ monocytes, and $37 \%$ unidentified large cells with foamy cytoplasms (some resembling those seen in Niemann-Pick disease). Occasional large cells displaying metachromatic granules were also noted. BM biopsy showed total effacement of the hematopoietic tissue by proliferating large anaplastic cells, differing in shape and size, with many bizarre forms. These cells were CD 45 negative by flow cytometry. Unfortunately, no additional studies could be performed. Autopsy specimens showed massive infiltration of the spleen and BM by malignant cells, generalized lymphadenopathy, in which the lymph nodes sinuses were filled by the atypical population, and malignant infiltration of portal tracts of the liver. There were large areas of necrosis in lymph nodes and spleen. By immunohistochemistry the atypical cells were positive for CD30, CD43, CD56, CD68, CD25, CD117. Weak positivity was found for CD163, CD4, and tryptase. ALK1, CD15, granzyme $\mathrm{B}$, perforin $\mathrm{B}, \mathrm{CD} 20$, BSAP, CD138, CD3, CD2, CD5, CD7, CD8, MPO, CD34, CD61, CD1a, S100, CKAE1/3, and EMA were negative. By molecular studies no Niemann-Pick or Gaucher disease-related mutations were found. The panel favored a diagnosis of myeloid neoplasm most consistent with MCL, although the possibility of MML was also considered.

\section{Sarcoma}

MCS, first described by Horny et al. [91], is an exceedingly rare malignancy characterized by a local tumor with destructive growth and metastatic potential, consisting of atypical MCs, without meeting the criteria of SM. The morphology of MCS can be highly heterogeneous and may differ from site to site within the same patient [33]. MCS consists of medium to very large pleomorphic or sometimes epithelioid cells with well-defined cell borders and oval or bilobed nuclei, or multinucleated tumor giant cells $[33,92]$. In a Giemsa stain, granules may be observed in the abnormal MCs. Eosinophilic granulocytes are often seen infiltrating the tumor and may be conspicuous [92]. The lesion may mimic several other tumors as it may be positive for antigens commonly associated with histiocytic lesions (CD68), myeloid sarcoma (CD117, weak lysozyme), ALCL (CD2, CD4, CD25, CD30, CD43), and melanoma (MITF), but can be correctly classified by its positivity for CD117 and/or tryptase, although tryptase staining may be weak [92-95]. Usually, MCS occurs de novo but cases secondary to CM [33], SM-AHN [96], or AML (case 230) do exist.

The largest and most recent review of MCS is by Monnier et al. [33], describing 23 cases of MCS with a median age at diagnosis of 41 years (range 1-77 years), the most common organ involved being bone (78\%), followed by
12

Pathobiology 2020;87:2-19 DOI: $10.1159 / 000504099$
Leguit/Hebeda/Kremer/van der Walt/ Gianelli/Tzankov/Orazi 
Table 4. MCS; the 3 workshop cases

\begin{tabular}{|c|c|c|c|}
\hline & Case 230 & Case 241 & Case 326 \\
\hline Gender, age & Male, 61 years & Male, 65 years & Male, 38 years \\
\hline History & $\begin{array}{l}\text { AML with trisomy } 8 \text { and mutations FLT3 } \\
\text { S451F, IDH2 R140Q, and SRSF2 P95H, for } \\
\text { which clinical and cytogenetic remission } \\
\text { achieved after HSCT }\end{array}$ & $\begin{array}{l}\text { Urothelial carcinoma of the renal } \\
\text { pelvis treated by nephrotomy }\end{array}$ & $\begin{array}{l}\text { Refractory T-cell lympoblastic leukemia/ } \\
\text { lymphoma (TCR-gamma delta+) treated with } \\
\text { post chemotherapy and allogeneic HSCT }\end{array}$ \\
\hline $\begin{array}{l}\text { Organs } \\
\text { involved }\end{array}$ & Left inferior pubic ramus & Multiple (lytic) bone lesions & Small bowel, ascites, liver, and omental nodules \\
\hline $\mathrm{IHC}$ & $\begin{array}{l}\text { Positive: CD117 } \\
\text { Weakly positive: tryptase } \\
\text { Negative: CD2, CD } 3, \text { CD } 25, \text { CD } 34\end{array}$ & $\begin{array}{l}\text { Positive: CD30, tryptase, CD117, } \\
\text { CD25 +/- } \\
\text { Negative: CD20, CD79a, CD3, CD5, } \\
\text { ALK, CD34, MPO, Glycophorin, } \\
\text { FVIII }\end{array}$ & $\begin{array}{l}\text { Positive: tryptase, CD68 (KP-1), CD123, CD117, } \\
\text { CD2, and CD25 } \\
\text { Negative: TdT }\end{array}$ \\
\hline Flow & $\begin{array}{l}\text { Positive: CD } 45, \text { CD } 33, \text { CD } 117, \text { CD } 13 \\
\text { Variable: CD } 38, \text { CD } 64 \text {, } \\
\text { Dim: CD7, CD } 4 \text { (negative to partially dim) } \\
\text { Negative: CD2, CD14, CD15, CD16, CD 25, } \\
\text { CD34, CD36, CD 56, CD123, HLA-DR, CD11b } \\
\text { (predominantly negative) }\end{array}$ & Not available & $\begin{array}{l}\text { Positive: CD117, CD123, CD25, CD2, CD33 } \\
\text { Dim: CD } 45, \text { CD } 13 \\
\text { Negative: CD34, MPO, TdT }\end{array}$ \\
\hline Mutations & $\begin{array}{l}\text { Imatinib-sensitive mutation KIT Y503_- } \\
\text { F504insAY in exon 9, along with IDH2 R140Q } \\
\text { and SRSF2 P95H mutations identical to the } \\
\text { initial AML }\end{array}$ & No KIT D816V mutation & $\begin{array}{l}\text { Complex karyotype: } 78-89, \mathrm{XXXX}, \operatorname{del}(3) \\
(\mathrm{p} 12 \mathrm{p} 26), \operatorname{add}(9)(\mathrm{p} 23), \operatorname{del}(9)(\mathrm{p} 12-24), \operatorname{add}(21) \\
\text { (p11.2)inc }[\mathrm{cp} 18] \\
\text { No KIT mutation }\end{array}$ \\
\hline Outcome & $\begin{array}{l}\text { Treated with irradiation and daily imatinib for } \\
5.5 \text { months, on which he achieved complete } \\
\text { remission. }\end{array}$ & $\begin{array}{l}\text { Treated with midostaurine without } \\
\text { effect, then dasatinib with } \\
\text { 5-azacytidine; survival: } 6 \text { months }\end{array}$ & $\begin{array}{l}\text { Palliative therapy } \\
\text { Survival: } 1 \text { month }\end{array}$ \\
\hline
\end{tabular}

the gastrointestinal tract (35\%), lymph nodes, skin (30\%), spleen $(26 \%)$, and liver (22\%). Symptoms related to MC mediators such as fever, flushing, diarrhea, and tachycardia occurred in one-third of all cases, and serum tryptase levels were usually high [33]. Two patients $(9 \%)$ had a history of CM as a child, and 1 patient (4\%) had familial mastocytosis [33]. Splenomegaly and hepatomegaly were present in 26 and $22 \%$, respectively [33]. KIT D $816 \mathrm{~V} \mathrm{mu-}$ tations were only present in about $20 \%$ of cases, about half had wild type KIT, and the remaining cases contain other KIT mutations [33]. As non-KIT D816V mutations and those with wild type KIT might be sensitive to imatinib, complete gene sequencing is necessary if no KIT D816V mutation is detected $[92,93,97,98]$. Evolution to MCL occurred in $30 \%$, and median survival time was 17 months [33]. Only 3 additional cases of MCS in humans have been published since; 2 located in the spine and 1 in the sternum $[95,99,100]$, the latter with an antecedent germ cell tumor with a D579del KIT mutation [100].

The workshop included 3 cases of MCS (Table 4); 2 localized in the bone and one with multiorgan involvement including the liver and small intestine. The bone lesion in case 230 proved to be clonally related to patients previous AML, suggesting that the MCS originated from the same preleukemic clone as the AML. The morphologic heterogeneity of MCS is well illustrated in Figure 4. It ranges from sheets of medium-sized cells with abundant, sometimes faintly granular cytoplasm, nuclear irregularities, and binucleated forms to a predominance of large pleomorphic cells with multinucleated tumor giant cells. Immunohistochemical and flow cytometric characteristics are shown in Table 4. All 3 cases showed malignant cells positive for CD117 and tryptase. CD30 and CD25 were positive in 2 cases. The third case (case 230) was negative for both CD30 and CD25. Survival was poor: 1 month in case 326 and 6 months in case 241 . However, the patient of case 230 achieved complete remission after treatment with irradiation and daily imatinib for 5.5 months, due to an imatinib-sensitive KIT Y503_F504insAY mutation in exon 9. None of the 3 workshop cases showed a KIT D816V mutation, but the imatinib-sensitive KIT exon 9 mutation in case 230 underlines the need to sequence the whole KIT gene in a case of MCS, so as not to miss mutations that might be sensi- 


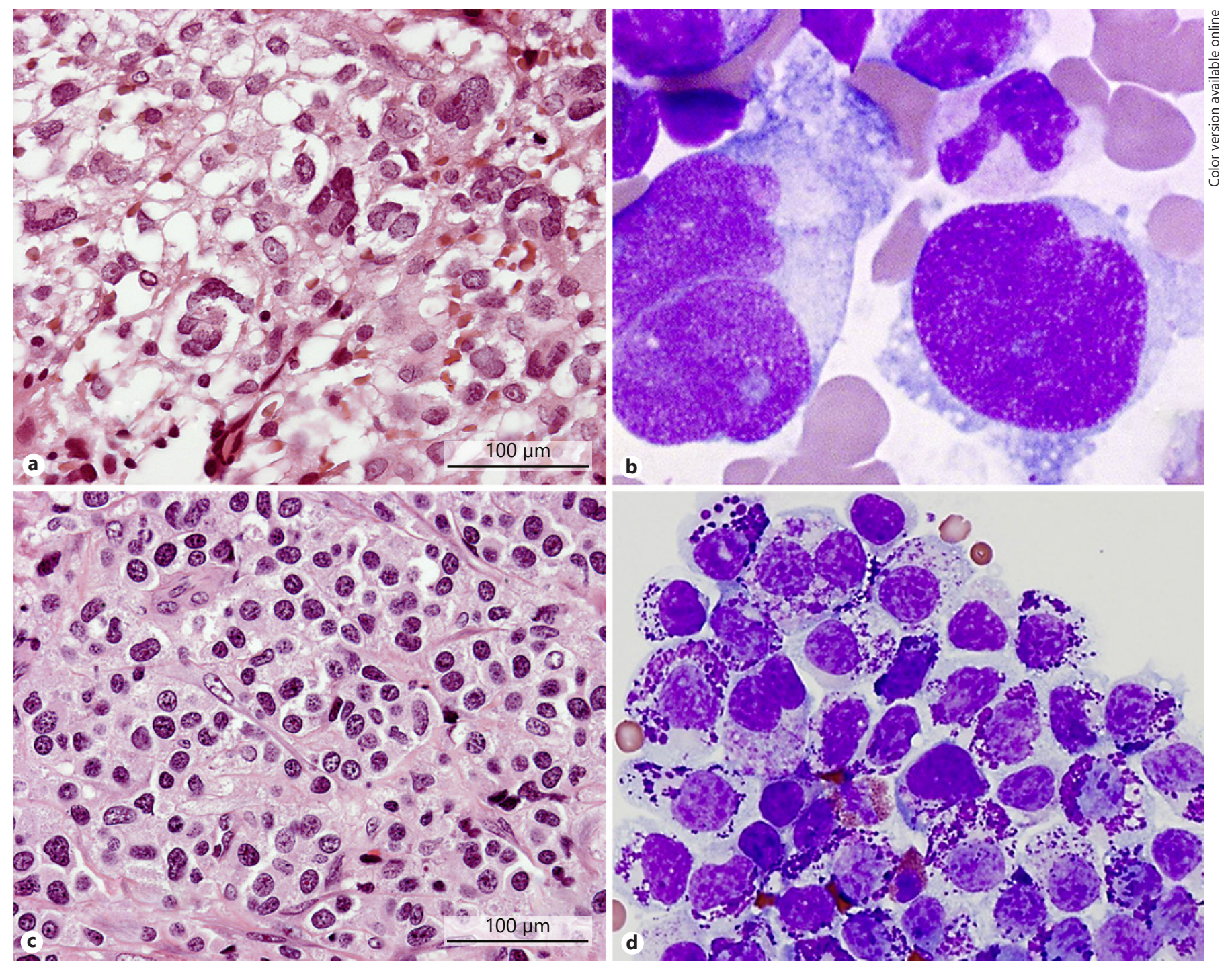

Fig. 4. MCs. a, b BM biopsy and smear showing large and highly atypical MCs with multinucleated tumor giant cells (case 241, Canioni et al.). c, d BM biopsy and smear showing medium sized to large atypical MCs with oval or bilobed nuclei with metachromatic granules (case 326, Chen et al.).

tive to targeted therapy. CD30 can be positive, as illustrated by case 241, making it easily confused with an ALK negative ALCL. MSCs often have a complex karyotype, as illustrated by case 326 .

\section{Disease Progression of Mastocytosis}

Disease progression of mastocytosis occurs when during the course of the disease; the MC proliferation acquires more aggressive features as seen in cases of ISM progressing to ASM or MCL, ASM progressing to MCL,
MCS progressing to MCL, or the acquisition or progression of an AHN component. Progression to acute MCL is associated with a rapid increase in MCs in the BM or blood, a rapid increase in serum tryptase (e.g., by $100 \mathrm{ng} /$ $\mathrm{mL}$ within a few weeks), or the occurrence of one or more C-findings [23]. Eventually, AML is the most frequent adverse manifestation of disease progression.

Of all SM patients included in one series, $4.1 \%$ experienced progression at follow-up and $6.1 \%$ died, $78.6 \%$ of which due to disease progression, including evolution to AML or complications related to organ involvement [32]. The risk of progression greatly depends on the type of SM 
(i.e., ISM, SSM, ASM, or SM-AHN) with ISM showing the lowest rate of disease progression. In one study, the cumulative probability of disease progression in ISM ranged from $1.7 \pm 1.2 \%$ at $5-10$ years to $8.4 \pm 5 \%$ at $20-25$ years [43]. In another published series, only $1 \%$ of ISM patients evolved to SSM, ASM, or AML (after 2, 11, and 21 years from SM diagnosis, respectively), but as many as $15 \%$ of patients with SSM showed progression (to ASM or AML) [32]. Direct leukemic transformation of ISM to MCL or AML is very rare $[31,32,55]$. The rate of leukemic transformation of ASM differs between studies and varies from $5 \%$ [54] to 32\% [32].

For ISM, powerful predictors of progression to a more aggressive form of disease include increased serum $\beta 2$ microglobulin level and presence of the KIT D816V mutation in all hematopoietic lineages (mutation in MCs + myeloid + lymphoid hematopoietic lineages) [43]. An immature BM MC phenotype by flow cytometric studies, together with aberrant CD25 expression in the absence of coexisting normal MC in the BM, is associated with multilineage involvement and shows a similar low progression free survival [44]. In addition, disease progression has been correlated with thrombocytopenia [32]. Regarding OS, risk factors in SM that have been identified are disease subtype, development of an AHN, age at diagnosis $>60$ years, thrombocytopenia, anemia, increased ALP and additional adverse non-KIT mutations [32, 36, 43, 57, 59, 101, 102]. Pardanani et al. [101] developed 2 risk models for assessing prognosis in SM; a clinical risk model and a hybrid clinicalmolecular risk model. The clinical risk model includes 5 clinical risk factors: age $>60$ years, $\mathrm{WHO}$-defined advanced SM versus ISM/SSM, thrombocytopenia $<150 \times 10^{9} / \mathrm{L}$, anemia defined as hemoglobin level below the sex-adjusted normal reference range, and increased serum ALP [101]. Survival was directly and proportionally correlated with the number of risk factors, with an outstanding prognosis for patients with 1 risk factor (median survival not reached) and poor outcome for patients with 4 or 5 risk factors (median survival 9-27 months) [101]. The clinical-molecular risk model was also based on 5 risk factors, including age $>60$ years, advanced versus ISM/SM, thrombocytopenia $<150 \times 10^{9} / \mathrm{L}$, increased serum ALP, and adverse mutations. Adverse mutations were not seen in patients with ISM/SSM in the investigated patient cohorts; therefore, the clinical-molecular risk model is primarily applicable in advanced SM [101].

\section{Progression as Illustrated by Workshop Cases}

Five cases submitted to the workshop illustrate progression of mastocytosis. Progression may occur step- wise, as seen in workshop case 208 (UP $\rightarrow$ SM [ISM]AHN [MDS-EB1] and then $\rightarrow$ myeloid sarcoma consistent with SM-AHN [AML]), case 294 (ISM $\rightarrow$ ASM $\rightarrow$ SM [ASM]-AHN [AML]) and case 247 (ISM $\rightarrow$ ASM $\rightarrow$ SM $[\mathrm{ASM}] \rightarrow \mathrm{SM}$ [ASM]-AHN [AML]). In 2 cases (cases 208 and 209), there was a history of UP. UP is the most common childhood form of mastocytosis, representing 60 $90 \%$ of cases. Childhood UP typically resolves by puberty, although rare cases have evolved into systemic disease in adulthood. The adult form of UP occurs on average at the age of 30 and seldom recovers spontaneously. Most adults with UP will show SM when fully investigated, especially when tryptase is elevated, and therefore these have been regarded in some studies as "probable ISM" [13, 52]. Case 208 was a 60 -year-old man with a history of UP, KIT D816V positive, with progression to SM (ISM)-AHN (MDS-EB-1). A meningeal biopsy showed a concomitant myeloid sarcoma. Cytogenetics showed monosomy of chromosome 7. Follow-up showed progression to SM (ISM)-AHN (AML). Case 209 was a 68-year-old woman with a 28 -year history of UP who developed MCL. The BM aspirate differential count showed $46 \%$ MCs and $1 \%$ myeloid blasts. The patient died and the autopsy showed infiltration of skin, liver, spleen, and lymph nodes by MCs.

Two workshop cases (case 294 and case 247) illustrate progression from ISM to ASM to SM-AHN. Case 294 was a 75 -year-old man, diagnosed 2 years earlier with ISM, who developed a rash, hepatosplenomegaly with portal venous hypertension, and lymphadenopathy. Biopsies of lymph node and liver showed involvement by SM, the latter establishing the diagnosis ASM. A KIT D816V mutation was present. Five years after the diagnosis of ASM, he developed confusion, abdominal pain, and vomiting. The peripheral blood smear showed around 20\% blasts (blasts included monoblasts and promonocytes) consistent with CMML-2 versus early AML. He expired within days. Case 247 was a 60 -year-old man with history of facial erythema and pruritus. Three years later, his skin lesions progressed to chest and limbs, without other symptoms; his BM showed 3\% morphologically atypical MCs with aberrant phenotype (CD2+, CD25+) consistent with ISM. Molecular studies at that time showed a KIT D816V mutation not only in MCs, but also in CD34+ cells, eosinophils, monocytes, and granulocytes. Skin lesions progressed despite treatment and 6 years later, he developed constitutional symptoms. A CT scan showed organomegaly, inguinal lymphadenopathy, pleural effusion, and lytic bone lesions, consistent with ASM. Mutation analysis demonstrated a TET2 M1701I mutation in addition to 
KIT D816V. On follow-up, the patient developed AML associated with an acquired additional RUNX1 R166Q mutation.

The fifth workshop case illustrating progression (case 158) was a 78-year-old man, who was diagnosed a year earlier with both a (triple negative) primary myelofibrosis (PMF) and ISM, that is, SM (ISM)-AHN (PMF). Molecular studies at that time showed the following mutations: KIT D816V, FBXW7 E117del variant, CSF3R E808K, and SRSF2 P95R. He was treated with ruxolitinib and later on with addition of midostaurin, resulting in clinical improvement for a few months, followed by worsening. BM investigation showed progressive disease with $21 \%$ atypical MCs consistent with MCL, aleukemic variant, and progression of the PMF with an increased number of mature-appearing monocytes in the aspirate. Molecular studies demonstrated an additional IDH2 R140Q mutation.

\section{In Summary}

- Advanced SM is rare and includes ASM, SM-AHN, and MCL. These aggressive subtypes of SM can occur de novo or represent disease progression from an indolent SM such as ISM or SSM.

- Presence of the KIT D816V mutation in several nonMC lineages (multilineage involvement) and presence of additional non-KIT mutations (especially SRSF2, $A S X L 1$, and RUNX1) are associated with adverse outcome, with AML as ultimate consequence in most cases.

- Chronic MCL can be discriminated from acute MCL by the lack of $\mathrm{C}$-findings and follows a less aggressive course. Aleukemic MCL is more common than typi$\mathrm{cal} /$ leukemic MCL, but both have a similar dismal outcome.

- Although uncommon (approximately $1.7 \%$ at 5 years), ISM may progress to ASM and MCL, as is illustrated by several workshop cases.

- SM-AHN includes a spectrum of diseases. The SM component may be either ISM or advanced SM and the AHN component is diverse. The frequency of involvement of the AHN cells by the KIT D816V mutation is dependent on the type of AHN, which might suggest different mechanisms of origin, with either a common progenitor cell, a multihit model with secondary KIT D816V mutation driving MC differentiation in a subclone, or coincidental presence of unrelated clones.
- MCS is rare, but its recognition has increased. MCS frequently and quickly becomes disseminated. It is CD117, tryptase, and often CD30 positive with variable CD25 and CD2 expression. CD30 positivity is a pitfall for mistaking MCS for an ALK-negative ALCL.

- MML is a rare disease and defined as mastocytic differentiation in an advanced myeloid neoplasms without evidence of SM. Criteria for SM are by definition not met, differentiating MML from MCL, and MML contains metachromatic blasts belonging to the MC lineage of $\geq 10 \%$ of all nucleated cells, differentiating MML from AML with tryptase-positive blasts.

- Appropriate sequencing of the KIT gene should be pursued for patients with SM and MCS that lack the imatinib-resistant KIT D816V mutation. This is especially true for MCL and MCS where non-KIT D816V mutations are relatively frequent.

\section{Acknowledgments}

The workshop panelists wish to thank the hosts for organizing the 18th European Association for Haematopathology meeting in Basel. The panel also likes to thank the case submitters for sharing their interesting and often challenging cases: Dr. Erica Reinig from Rochester, NY, USA (case 113); Dr. Anna Green from London, UK (case 208); Dr. Daniel Martinez from Barcelona, Spain (case 247); Dr. Elizabeth Margolskee from New York, NY, USA (case 209); Dr. Hywyn Churchill from Dallas, TX, USA (case 230); Dr. Jennifer Oliveira from Rochester, NY, USA (case 160); Dr. Danielle Canioni from Paris, France (case 241); Dr. Yi-Hua Chen from Chicago, IL, USA (case 326); Dr. Gordana K. Petrusevska from Skopje, Macedonia (case 111); Dr. Prabhjot Kaur from Lebanon, PA, USA (case 239); Dr. Sarah Choi from Chicago, IL, USA (case 158); Dr. Brian Bockelman from Hersey, PA, USA (case 294); Dr. Rashmi S. Goswamy from Houston, USA (case 331); Dr. Francisco J. Llamas Gutierrez from Rennes, Frances (case 319); Dr. Keyur P. Patel from Houston, TX, USA (case 293); Dr. Claudiu V. Cotta from Cleveland, OH, USA (case 349) and Dr. Bogna Ziarkiewicz-Wróblewska from Warsaw, Poland (case 193).

\section{Statement of Ethics}

This article does not contain any studies with human participants or animals performed by any of the authors.

\section{Disclosure Statement}

The authors declare that they have no conflict of interest.
Leguit/Hebeda/Kremer/van der Walt/ Gianelli/Tzankov/Orazi 


\section{References}

1 Kirshenbaum AS, Goff JP, Semere T, Foster B, Scott LM, Metcalfe DD. Demonstration that human mast cells arise from a progenitor cell population that is CD34(+), c-kit(+), and expresses aminopeptidase $\mathrm{N}$ (CD13). Blood. 1999 Oct;94(7):2333-42.

2 Galli SJ, Nakae S, Tsai M. Mast cells in the development of adaptive immune responses. Nat Immunol. 2005 Feb;6(2):135-42.

3 da Silva EZ, Jamur MC, Oliver C. Mast cell function: a new vision of an old cell. J Histochem Cytochem. 2014 Oct;62(10):698-738.

4 Reber LL, Sibilano R, Mukai K, Galli SJ. Potential effector and immunoregulatory functions of mast cells in mucosal immunity. $\mathrm{Mu}$ cosal Immunol. 2015 May;8(3):444-63.

5 Metcalfe DD. Mast cells and mastocytosis. Blood. 2008 Aug;112(4):946-56.

6 Ashman LK. The biology of stem cell factor and its receptor C-kit. Int J Biochem Cell Biol. 1999 Oct;31(10):1037-51.

7 Miettinen M, Lasota J. KIT (CD117): a review on expression in normal and neoplastic tissues, and mutations and their clinicopathologic correlation. Appl Immunohistochem Mol Morphol. 2005 Sep;13(3):205-20.

8 Ashman LK, Cambareri AC, To LB, Levinsky RJ, Juttner CA. Expression of the YB5.B8 antigen (c-kit proto-oncogene product) in normal human bone marrow. Blood. 1991 Jul;78(1):30-7.

9 Papayannopoulou T, Brice M, Broudy VC, Zsebo KM. Isolation of c-kit receptor-expressing cells from bone marrow, peripheral blood, and fetal liver: functional properties and composite antigenic profile. Blood. 1991 Sep;78(6):1403-12.

10 To LB, Haylock DN, Dowse T, Simmons PJ, Trimboli S, Ashman LK, et al. A comparative study of the phenotype and proliferative capacity of peripheral blood (PB) CD34+ cells mobilized by four different protocols and those of steady-phase PB and bone marrow CD34+ cells. Blood. 1994 Nov;84(9):2930-9.

11 Akin C. Clonality and molecular pathogenesis of mastocytosis. Acta Haematol. 2005; 114(1):61-9.

12 Valent P. Mastocytosis: a paradigmatic example of a rare disease with complex biology and pathology. Am J Cancer Res. 2013 Apr;3(2): $159-72$.

13 Valent P, Akin C, Escribano L, Födinger M, Hartmann K, Brockow K, et al. Standards and standardization in mastocytosis: consensus statements on diagnostics, treatment recommendations and response criteria. Eur J Clin Invest. 2007 Jun;37(6):435-53.

14 Horny HP, Akin C, Arber DA, et al. Mastocytosis. In: Swerdlow S, Campo E, Harris N, et al., editors. WHO classification of tumours of haematopoietic and lymphoid tissues, 4th revise. Lyon, France: IARC Press; 2017.

15 Pardanani A. Systemic mastocytosis in adults: 2019 update on diagnosis, risk stratification and management. Am J Hematol. 2019 Mar; 94(3):363-77.
16 Laine E, Chauvot de Beauchêne I, Perahia D, Auclair C, Tchertanov L. Mutation D816V alters the internal structure and dynamics of $\mathrm{c}$ KIT receptor cytoplasmic region: implications for dimerization and activation mechanisms. PLOS Comput Biol. 2011 Jun;7(6):e1002068.

17 Nagata H, Worobec AS, Oh CK, Chowdhury BA, Tannenbaum S, Suzuki Y, et al. Identification of a point mutation in the catalytic domain of the protooncogene c-kit in peripheral blood mononuclear cells of patients who have mastocytosis with an associated hematologic disorder. Proc Natl Acad Sci USA. 1995 Nov;92(23):10560-4.

18 Arock M, Sotlar K, Akin C, Broesby-Olsen S, Hoermann G, Escribano L, et al. KIT mutation analysis in mast cell neoplasms: recommendations of the European Competence Network on Mastocytosis. Leukemia. 2015 Jun;29(6):1223-32.

19 Akin C, Valent P, Metcalfe DD. Mast cell activation syndrome: proposed diagnostic criteria. J Allergy Clin Immunol. 2010 Dec;126(6): 1099-104.e4.

20 Valent P. Mast cell activation syndromes: definition and classification. Allergy. $2013 \mathrm{Apr}$; 68(4):417-24.

21 Valent P, Akin C, Arock M, Brockow K, Butterfield JH, Carter MC, et al. Definitions, criteria and global classification of mast cell disorders with special reference to mast cell activation syndromes: a consensus proposal. Int Arch Allergy Immunol. 2012;157(3):215-25.

22 Sperr WR, Escribano L, Jordan JH, Schernthaner GH, Kundi M, Horny HP, et al. Morphologic properties of neoplastic mast cells: delineation of stages of maturation and implication for cytological grading of mastocytosis. Leuk Res. 2001 Jul;25(7):529-36.

23 Valent P, Sotlar K, Sperr WR, Escribano L, Yavuz S, Reiter A, et al. Refined diagnostic criteria and classification of mast cell leukemia (MCL) and myelomastocytic leukemia (MML): a consensus proposal. Ann Oncol. 2014 Sep;25(9):1691-700.

24 Garcia-Montero AC, Jara-Acevedo M, Teodosio C, Sanchez ML, Nunez R, Prados A, et al. KIT mutation in mast cells and other bone marrow hematopoietic cell lineages in systemic mast cell disorders: a prospective study of the Spanish Network on Mastocytosis (REMA) in a series of 113 patients. Blood. 2006 Oct; 108(7):2366-72.

25 Álvarez-Twose I, Jara-Acevedo M, Morgado JM, García-Montero A, Sánchez-Muñoz L, Teodósio C, et al. Clinical, immunophenotypic, and molecular characteristics of well-differentiated systemic mastocytosis. J Allergy Clin Immunol. 2016 Jan;137(1):168-178.e1.

26 Teodosio C, García-Montero AC, Jara-Acevedo M, Sánchez-Muñoz L, Alvarez-Twose I, Núñez R, et al. Mast cells from different molecular and prognostic subtypes of systemic mastocytosis display distinct immunophenotypes. J Allergy Clin Immunol. 2010 Mar; 125(3):719-26.
27 Sotlar K, Cerny-Reiterer S, Petat-Dutter K, Hessel H, Berezowska S, Müllauer L, et al. Aberrant expression of CD30 in neoplastic mast cells in high-grade mastocytosis. Mod Pathol. 2011 Apr;24(4):585-95.

28 Morgado JM, Perbellini O, Johnson RC, Teodósio C, Matito A, Álvarez-Twose I, et al. CD30 expression by bone marrow mast cells from different diagnostic variants of systemic mastocytosis. Histopathology. 2013 Dec: 63(6):780-7.

29 Russano de Paiva Silva G, Tournier E, Sarian LO, Bulai-Livideanu C, Delsol G, Lamant L, et al. Prevalence of CD30 immunostaining in neoplastic mast cells: A retrospective immunohistochemical study. Medicine (Baltimore). 2018 May;97(21):e10642.

30 Georgin-Lavialle S, Lhermitte L, Dubreuil P, Chandesris MO, Hermine O, Damaj G. Mast cell leukemia. Blood. 2013 Feb;121(8):1285-95.

31 Jawhar M, Schwaab J, Meggendorfer M, Naumann N, Horny HP, Sotlar K, et al. The clinical and molecular diversity of mast cell leukemia with or without associated hematologic neoplasm. Haematologica. 2017 Jun;102(6): 1035-43

32 Pieri L, Bonadonna P, Elena C, Papayannidis C, Grifoni FI, Rondoni M, et al. Clinical presentation and management practice of systemic mastocytosis. A survey on 460 Italian patients. Am J Hematol. 2016 Jul;91(7):692-9.

33 Monnier J, Georgin-Lavialle S, Canioni D, Lhermitte L, Soussan M, Arock M, et al. Mast cell sarcoma: new cases and literature review. Oncotarget. 2016 Oct;7(40):66299-309.

34 Akin C, Kirshenbaum AS, Semere T, Worobec AS, Scott LM, Metcalfe DD. Analysis of the surface expression of c-kit and occurrence of the c-kit Asp816 Val activating mutation in $\mathrm{T}$ cells, B cells, and myelomonocytic cells in patients with mastocytosis. Exp Hematol. 2000 Feb;28(2):140-7.

35 Yavuz AS, Lipsky PE, Yavuz S, Metcalfe DD, Akin C. Evidence for the involvement of a hematopoietic progenitor cell in systemic mastocytosis from single-cell analysis of mutations in the c-kit gene. Blood. $2002 \mathrm{Jul} ; 100(2)$ : 661-5.

36 Schwaab J, Schnittger S, Sotlar K, Walz C, Fabarius A, Pfirrmann M, et al. Comprehensive mutational profiling in advanced systemic mastocytosis. Blood. 2013 Oct;122(14): 2460-6.

37 Taylor ML, Sehgal D, Raffeld M, Obiakor H Akin C, Mage RG, et al. Demonstration that mast cells, T cells, and B cells bearing the activating kit mutation D816V occur in clusters within the marrow of patients with mastocytosis. J Mol Diagn. 2004 Nov;6(4):335-42.

38 Sotlar K, Colak S, Bache A, Berezowska S, Krokowski M, Bültmann B, et al. Variable presence of KITD816V in clonal haematological non-mast cell lineage diseases associated with systemic mastocytosis (SM-AHNMD). J Pathol. 2010 Apr;220(5):586-95. 
39 Sotlar K, Marafioti T, Griesser H, Theil J, Aepinus C, Jaussi R, et al. Detection of c-kit mutation Asp 816 to Val in microdissected bone marrow infiltrates in a case of systemic mastocytosis associated with chronic myelomonocytic leukaemia. Mol Pathol. 2000 Aug; 53(4):188-93.

40 Pardanani A, Reeder T, Li CY, Tefferi A. Eosinophils are derived from the neoplastic clone in patients with systemic mastocytosis and eosinophilia. Leuk Res. 2003 Oct;27(10):883-5.

41 Kristensen T, Broesby-Olsen S, Vestergaard $\mathrm{H}$, Bindslev-Jensen C, Møller MB; Mastocytosis Centre Odense University Hospital (MastOUH). Circulating KIT D816V mutation-positive non-mast cells in peripheral blood are characteristic of indolent systemic mastocytosis. Eur J Haematol. 2012 Jul;89(1): 42-6.

42 Georgin-Lavialle S, Lhermitte L, Baude C, Barete S, Bruneau J, Launay JM, et al. Blood $\mathrm{CD} 34-\mathrm{c}-\mathrm{Kit}+$ cell rate correlates with aggressive forms of systemic mastocytosis and behaves like a mast cell precursor. Blood. 2011 Nov;118(19):5246-9.

43 Escribano L, Álvarez-Twose I, Sánchez-Muñoz L, Garcia-Montero A, Núñez R, Almeida $\mathrm{J}$, et al. Prognosis in adult indolent systemic mastocytosis: a long-term study of the Spanish Network on Mastocytosis in a series of 145 patients. J Allergy Clin Immunol. 2009 Sep; 124(3):514-21.

44 Teodosio C, García-Montero AC, Jara-Acevedo M, Alvarez-Twose I, Sánchez-Muñoz L, Almeida J, et al. An immature immunophenotype of bone marrow mast cells predicts for multilineage D816V KIT mutation in systemic mastocytosis. Leukemia. 2012 May;26(5):951-8.

45 Hoermann G, Gleixner KV, Dinu GE, Kundi M, Greiner G, Wimazal F, et al. The KIT D816V allele burden predicts survival in patients with mastocytosis and correlates with the WHO type of the disease. Allergy. 2014 Jun;69(6):810-3.

46 Erben P, Schwaab J, Metzgeroth G, Horny HP, Jawhar M, Sotlar K, et al. The KIT D816V expressed allele burden for diagnosis and disease monitoring of systemic mastocytosis. Ann Hematol. 2014 Jan;93(1):81-8.

47 Kristensen T, Vestergaard H, Bindslev-Jensen C, Møller MB, Broesby-Olsen S; Mastocytosis Centre, Odense University Hospital (MastOUH). Sensitive KIT D816V mutation analysis of blood as a diagnostic test in mastocytosis. Am J Hematol. 2014 May;89(5):493-8.

48 Hanssens K, Brenet F, Agopian J, GeorginLavialle S, Damaj G, Cabaret L, et al. SRSF2p95 hotspot mutation is highly associated with advanced forms of mastocytosis and mutations in epigenetic regulator genes. Haematologica. 2014 May;99(5):830-5.

49 Jawhar M, Schwaab J, Schnittger S, Sotlar K, Horny HP, Metzgeroth G, et al. Molecular profiling of myeloid progenitor cells in multimutated advanced systemic mastocytosis identifies KIT D816V as a distinct and late event. Leukemia. 2015 May;29(5):1115-22.
50 Horny HP, Sotlar K, Sperr WR, Valent P. Systemic mastocytosis with associated clonal haematological non-mast cell lineage diseases: a histopathological challenge. J Clin Pathol. 2004 Jun;57(6):604-8.

51 Cohen SS, Skovbo S, Vestergaard H, Kristensen T, Møller M, Bindslev-Jensen C, et al. Epidemiology of systemic mastocytosis in Denmark. Br J Haematol. 2014 Aug;166(4): 521-8.

52 van Doormaal JJ, Arends S, Brunekreeft KL, van der Wal VB, Sietsma J, van Voorst Vader $\mathrm{PC}$, et al. Prevalence of indolent systemic mastocytosis in a Dutch region. J Allergy Clin Immunol. 2013 May;131(5):1429-31.e1.

53 Hermans MA, Rietveld MJ, van Laar JA, Dalm VA, Verburg M, Pasmans SG, et al. Systemic mastocytosis: A cohort study on clinical characteristics of 136 patients in a large tertiary centre. Eur J Intern Med. 2016 May;30: 25-30.

54 Lim KH, Tefferi A, Lasho TL, Finke C, Patnaik M, Butterfield JH, et al. Systemic mastocytosis in 342 consecutive adults: survival studies and prognostic factors. Blood. 2009 Jun;113(23):5727-36.

55 Valent P, Oude Elberink JN, Gorska A, Lange M, Zanotti R, van Anrooij B, et al.; Study Group of the European Competence Network on Mastocytosis (ECNM). The Data Registry of the European Competence Network on Mastocytosis (ECNM): Set Up, Projects, and Perspectives. J Allergy Clin Immunol Pract. 2019 Jan;7(1):81-7.

56 Jain P, Wang S, Patel KP, Sarwari N, Cortes J, Kantarjian H, et al. Mast cell leukemia (MCL): clinico-pathologic and molecular features and survival outcome. Leuk Res. 2017 Aug;59: 105-9.

57 Damaj G, Joris M, Chandesris O, Hanssens K, Soucie E, Canioni D, et al. ASXL1 but not TET2 mutations adversely impact overall survival of patients suffering systemic mastocytosis with associated clonal hematologic nonmast-cell diseases. PLoS One. 2014 Jan; 9(1):e85362.

58 Naumann N, Jawhar M, Schwaab J, Kluger S, Lübke J, Metzgeroth $G$, et al. Incidence and prognostic impact of cytogenetic aberrations in patients with systemic mastocytosis. Genes Chromosomes Cancer. 2018 May;57(5):252-9.

59 Jawhar M, Schwaab J, Schnittger S, Meggendorfer M, Pfirrmann M, Sotlar K, et al. Additional mutations in SRSF2, ASXL1 and/or RUNX1 identify a high-risk group of patients with KIT D816V(+) advanced systemic mastocytosis. Leukemia. 2016 Jan;30(1):136-43.

60 Pardanani A. Systemic mastocytosis in adults: 2017 update on diagnosis, risk stratification and management. Am J Hematol. 2016 Nov; 91(11):1146-59.

61 Traina F, Visconte V, Jankowska AM Makishima H, O'Keefe CL, Elson P, et al. Single nucleotide polymorphism array lesions, TET2, DNMT3A, ASXL1 and CBL mutations are present in systemic mastocytosis. PLoS One. 2012;7(8):e43090.
62 Soucie E, Hanssens K, Mercher T, GeorginLavialle S, Damaj G, Livideanu C, et al. In aggressive forms of mastocytosis, TET2 loss cooperates with c-KITD816V to transform mast cells. Blood. 2012 Dec;120(24):4846-9.

63 Wang SA, Hutchinson L, Tang G, Chen SS, Miron PM, Huh YO, et al. Systemic mastocytosis with associated clonal hematological non-mast cell lineage disease: clinical significance and comparison of chomosomal abnormalities in SM and AHNMD components. Am J Hematol. 2013 Mar;88(3):21924.

64 Shah S, Pardanani A, Elala YC, Lasho TL, Patnaik MM, Reichard KK, et al. Cytogenetic abnormalities in systemic mastocytosis: WHO subcategory-specific incidence and prognostic impact among 348 informative cases. Am J Hematol. 2018 Dec;93(12):1461-6.

65 Pardanani A, Tefferi A. Systemic mastocytosis in adults: a review on prognosis and treatment based on 342 Mayo Clinic patients and current literature. Curr Opin Hematol. 2010 Mar; 17(2):125-32.

66 Valent P, Akin C, Metcalfe DD. Mastocytosis: 2016 updated WHO classification and novel emerging treatment concepts. Blood. 2017 Mar;129(11):1420-7.

67 Budnik J, Milano MT. A registry-based analysis of survival outcomes in mast cell leukemia. Leuk Res. 2019 Mar;78:24-8.

68 Sperr WR, Horny HP, Lechner K, Valent P. Clinical and biologic diversity of leukemias occurring in patients with mastocytosis. Leuk Lymphoma. 2000 May;37(5-6):473-86.

69 Pardanani A, Lim KH, Lasho TL, Finke C, McClure RF, Li CY, et al. Prognostically relevant breakdown of 123 patients with systemic mastocytosis associated with other myeloid malignancies. Blood. 2009 Oct;114(18):3769_ 72.

70 Travis WD, Li CY, Yam LT, Bergstralh EJ, Swee RG. Significance of systemic mast cell disease with associated hematologic disorders. Cancer. 1988 Sep;62(5):965-72.

71 Savage NM, Johnson RC, Gotlib J, George TI. Myeloid and lymphoid Neoplasms with FGFR1 abnormalities: diagnostic and therapeutic challenges. Am J Hematol. 2013 May; 88(5):427-30.

72 Chaffin JM, Savage NM. Myeloid and lymphoid neoplasms with eosinophilia and abnormalities of PDGFRA, PDGFRB, FGFR1, or $\mathrm{t}(8 ; 9)(\mathrm{p} 22 ; \mathrm{p} 24.1) ;$ PCM1-JAK2. In: Chang CC, Ohgami R (eds). Precision Molecular Pathology of Myeloid Neoplasms. Springer: Molecular Pathology Library; 2018.

73 Pardanani A. Systemic mastocytosis in adults: 2017 update on diagnosis, risk stratification and management. Available from: https://doi. org/https://doi.org/10.1002/ajh.09111.

74 Jawhar M, Naumann N, Schwaab J, Baurmann H, Casper J, Dang TA, et al. Imatinib in myeloid/lymphoid neoplasms with eosinophilia and rearrangement of PDGFRB in chronic or blast phase. Ann Hematol. 2017 Sep;96(9):1463-70. 
75 Fritsche-Polanz R, Fritz M, Huber A, Sotlar K, Sperr WR, Mannhalter C, et al. High frequency of concomitant mastocytosis in patients with acute myeloid leukemia exhibiting the transforming KIT mutation D816V. Mol Oncol. 2010 Aug;4(4):335-46.

76 Ferrao PT, Gonda TJ, Ashman LK. Constitutively active mutant D816VKit induces megakayocyte and mast cell differentiation of early haemopoietic cells from murine foetal liver. Leuk Res. 2003 Jun;27(6):547-55.

77 Pardanani A, Lasho T, Elala Y, Wassie E, Finke C, Reichard KK, et al. Next-generation sequencing in systemic mastocytosis: derivation of a mutation-augmented clinical prognostic model for survival. Am J Hematol. 2016 Sep;91(9):888-93.

78 Johnson RC, Savage NM, Chiang T, Gotlib JR, Cherry AM, Arber DA, et al. Hidden mastocytosis in acute myeloid leukemia with $\mathrm{t}(8 ; 21)$ (q22;q22). Am J Clin Pathol. 2013 Oct;140(4): 525-35.

79 Nichols CR, Roth BJ, Heerema N, Griep J, Tri$\cot \mathrm{G}$. Hematologic neoplasia associated with primary mediastinal germ-cell tumors. N Engl J Med. 1990 May;322(20):1425-9.

80 Orazi A, Neiman RS, Ulbright TM, Heerema NA, John K, Nichols CR. Hematopoietic precursor cells within the yolk sac tumor component are the source of secondary hematopoietic malignancies in patients with mediastinal germ cell tumors. Cancer. 1993 Jun;71(12): 3873-81.

81 Moreira AL, Chain JK, Looijenga LH, et al. Germ cell tumours of the mediastinum. In: Travis WD, Brambilla E, Burke AP, et al., editors. WHO classificatio of tumours of the lung, pleura, Tthymus and heart. 4th ed. Lyon, France: IARC Press; 2015.

82 Song SY, Ko YH, Ahn G. Mediastinal germ cell tumor associated with histiocytic sarcoma of spleen: case report of an unusual association. Int J Surg Pathol. 2005 Jul;13(3):299303.

83 Shinoda H, Yoshida A, Teruya-Feldstein J. Malignant histiocytoses/disseminated histiocytic sarcoma with hemophagocytic syndrome in a patient with mediastinal germ cell tumor. Appl Immunohistochem Mol Morphol. 2009 Jul;17(4):338-44.
84 Tzankov A, Kremer M, Leguit R, Orazi A, van der Walt J, Gianelli U, et al. Histiocytic cell neoplasms involving the bone marrow: summary of the workshop cases submitted to the 18th Meeting of the European Association for Haematopathology (EAHP) organized by the European Bone Marrow Working Group, Basel 2016. Ann Hematol. 2018 Nov;97(11): 2117-28.

85 Chariot P, Monnet I, LeLong F, Chleq C, Droz JP, de Cremoux H. Systemic mast cell disease associated with primary mediastinal germ cell tumor. Am J Med. 1991 Mar;90(3):381-5.

86 Sperr WR, Drach J, Hauswirth AW, Ackermann J, Mitterbauer M, Mitterbauer G, et al. Myelomastocytic leukemia: evidence for the origin of mast cells from the leukemic clone and eradication by allogeneic stem cell transplantation. Clin Cancer Res. 2005 Oct;11(19 Pt 1):6787-92.

87 Arredondo AR, Gotlib J, Shier L, Medeiros B, Wong K, Cherry A, et al. Myelomastocytic leukemia versus mast cell leukemia versus systemic mastocytosis associated with acute myeloid leukemia: a diagnostic challenge. Am J Hematol. 2010 Aug;85(8):600-6.

88 Horny HP, Sotlar K, Reiter A, Valent P. Myelomastocytic leukemia: histopathological features, diagnostic criteria and differential diagnosis. Expert Rev Hematol. 2014 Aug; 7(4):431-7.

89 Valent P, Samorapoompichit P, Sperr WR, Horny HP, Lechner K. Myelomastocytic leukemia: myeloid neoplasm characterized by partial differentiation of mast cell-lineage cells. Hematol J. 2002;3(2):90-4.

90 Rich A, Sun J, Aldayel AS, Yin CC, Medeiros LJ, Konoplev S. Myelomastocytic leukemia with aberrant CD25 expression: case report and review of the literature. Clin Lymphoma Myeloma Leuk. 2014 Oct;14(5):e173-7.

91 Horny HP, Parwaresch MR, Kaiserling E, Müller K, Olbermann M, Mainzer K, et al. Mast cell sarcoma of the larynx. J Clin Pathol. 1986 Jun;39(6):596-602.

92 Ryan RJ, Akin C, Castells M, Wills M, Selig MK, Nielsen GP, et al. Mast cell sarcoma: a rare and potentially under-recognized diagnostic entity with specific therapeutic implications. Mod Pathol. 2013 Apr;26(4):533-43.
93 Bautista-Quach MA, Booth CL, Kheradpour A, Zuppan CW, Rowsell EH, Weiss L, et al. Mast cell sarcoma in an infant: a case report and review of the literature. J Pediatr Hematol Oncol. 2013 May;35(4):315-20.

94 Georgin-Lavialle S, Aguilar C, Guieze R, Lhermitte L, Bruneau J, Fraitag S, et al. Mast cell sarcoma: a rare and aggressive entityreport of two cases and review of the literature. J Clin Oncol. 2013 Feb;31(6):e90-7.

95 He F, Horny HP, Boone J, Raza A, Griffith M, Hurley P, et al. Anaplastic mast cell sarcoma: a unique pathologic entity in mastocytosis. Leuk Lymphoma. 2017 Jun;58(6): $1515-7$.

96 Schwaab J, Horny HP, Jonescheit J, Metzgeroth G, Schafhausen P, Gaiser T, et al. Mast cell sarcoma mimicking metastatic colon carcinoma. Ann Hematol. 2014 Jun; 93(6):1067-9.

97 Ma HB, Xu X, Liu WP, Chang H, Zeng F, Wang YC. Successful treatment of mast cell sarcoma of the uterus with imatinib. Int Hematol. 2011 Nov;94(5):491-4.

98 Bugalia A, Abraham A, Balasubramanian P, Srivastava A, Nair S. Mast cell sarcoma of the small intestine: a case report. J Clin Pathol. 2011 Nov;64(11):1035-7.

99 Ravanpay AC, Fromm JR, Edlefsen KL, Martin P, Chesnut R. The first report of human primary thoracic spine mast cell sarcoma: a case report. Clin Neuropathol. 2018 $\mathrm{Jan} / \mathrm{Feb} ; 37(1): 28-35$

100 Yamashita A, Saito T, Akaike K, Arakawa A, Yoshida A, Kikuchi K, et al. Mast cell sarcoma of the sternum, clonally related to an antecedent germ cell tumor with a novel D579del KIT mutation. Virchows Arch. 2017 May;470(5):583-8.

101 Pardanani A, Shah S, Mannelli F, Elala YC, Guglielmelli P, Lasho TL, et al. Mayo alliance prognostic system for mastocytosis: clinical and hybrid clinical-molecular models. Blood Adv. 2018 Nov;2(21):2964-72.

102 Pardanani A. Systemic mastocytosis: evolving lessons from large patient registry datasets. Am J Hematol. 2016 Jul;91(7):654-5. 